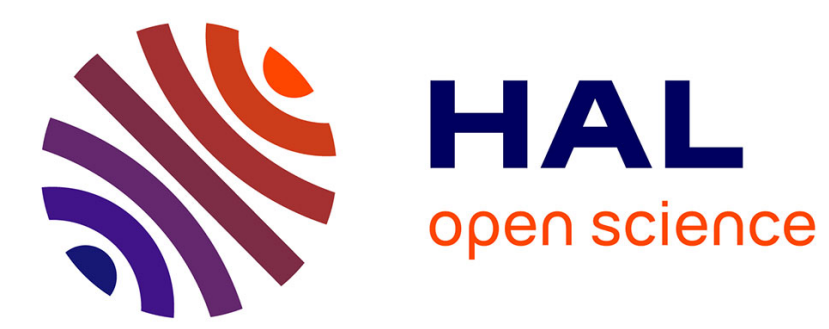

\title{
Real Estate and Rental Markets during Covid Times
}

\author{
Bertrand Achou, Hippolyte d'Albis, Eleni Iliopulos
}

\section{To cite this version:}

Bertrand Achou, Hippolyte d'Albis, Eleni Iliopulos. Real Estate and Rental Markets during Covid

Times. 2021. halshs-03231807

\section{HAL Id: halshs-03231807 \\ https://shs.hal.science/halshs-03231807}

Preprint submitted on 21 May 2021

HAL is a multi-disciplinary open access archive for the deposit and dissemination of scientific research documents, whether they are published or not. The documents may come from teaching and research institutions in France or abroad, or from public or private research centers.
L'archive ouverte pluridisciplinaire HAL, est destinée au dépôt et à la diffusion de documents scientifiques de niveau recherche, publiés ou non, émanant des établissements d'enseignement et de recherche français ou étrangers, des laboratoires publics ou privés. 


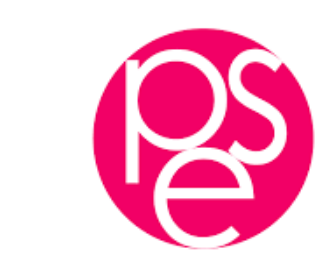

PARISSCHOOL OFECONOMICS
ECOLED'ECONOMIEDE PARIS

WORKING PAPER N ${ }^{\circ} 2021-34$

\title{
Real Estate and Rental Markets during Covid Times
}

\author{
Bertrand Achou \\ Hippolyte d'Albis \\ Eleni Iliopulos
}

JEL Codes: E3, G1, C1, I3.

Keywords: housing; rental markets; collateral constraints; financial frictions; HANK models.

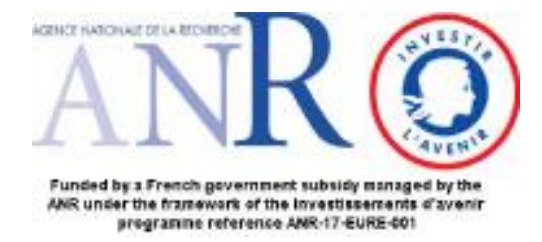




\title{
Real Estate and Rental Markets during Covid Times*
}

\author{
Bertrand Achouł Hippolyte d’Albis; Eleni Iliopulos ${ }^{\S}$
}

May 18, 2021

\begin{abstract}
In this work we introduce a general equilibrium model with landlords, indebted owner-occupiers and renters to study housing markets' dynamics. We estimate it by using standard Bayesian methods and match the US data of the last decades. This framework is particularly suited to explain current trends on housing markets. We highlight the crucial relationship between interest rates, house prices and rents, and argue that it helps understanding the main driving forces. Our analysis suggests that current developments on housing markets can play a role for a recovery from the Covid pandemic as they have an expansionary effect on aggregate output. Moreover, we account for the heterogeneous impact of crisis-induced policies depending on agents' status on the housing market. We show how, despite an increase in housing prices, the welfare of landlords has been negatively hit. This is associated to the joint decrease in returns on housing and financial assets that reduces their financial incomes.
\end{abstract}

Keywords: Housing; Rental Markets; Collateral Constraints; Financial Frictions; HANK Models.

JEL Classification Numbers: E3, G1, C1, I3

${ }^{*}$ We thank Stephane Adjemian, Andrea Ferrero, François Langot, Xavier Ragot, Fabien Tripier, Bertrand Wigniolle as well as all participants at the seminar at the University of Maine for interesting discussion. The usual disclaimer applies.

${ }^{\dagger}$ Bertrand Achou, Retirement and Savings Institute HEC Montréal (mailto: bertrand.achou@gmail.com)

${ }^{\ddagger}$ Hippolyte d’Albis, CNRS and Paris School of Economics (mailto: hippolyte.dalbis@psemail.eu)

${ }^{\S}$ Corresponding author: Eleni Iliopulos, EPEE, University of Evry, Univ. Paris-Saclay and Cepremap. Departement of economics, 4 Bd François Mitterrand, 91025 Évry Cedex - France (mailto: eleni.iliopulos@univ-evry.fr) 


\section{Introduction}

While the US economy was struggling to survive the Covid-19 pandemic, its housing market has experienced a boom. As highlighted by several scholars, this is a "remarkable record" (Robert Shiller, 3 July 2020 on the New York Times). As emphasized by The Economist (September the 30th 2020), while they fell by about $10 \%$ during the 2008 financial crisis, house prices are currently rising $^{1}$ with an annual rate of 5\% in G7 countries. More surprisingly, starting from spring 2020, rents are significantly below the trend. While the financial crisis represented a negative shock on housing markets, current developments seem to be closer to a boom episode and deserve a deeper understanding. ${ }^{2}$

These surprising dynamics trigger two crucial questions. Firstly, what are the roots of current trends? Indeed, even if several usual suspects can be listed (such as changes in preferences and in policies), the debate is still open (see Zhao (43)). Secondly, what are the welfare implications of those trends on inequality and, more precisely, on the divide between homeowners and renters? Indeed, as emphasized by Christophers (7) among others, this divide is fundamental in that the very-key tenure difference among households is renting vs home ownership.

In light of the above considerations we study housing market dynamics in a framework where we explicitly incorporate rental markets. Indeed, in the US about a third of the population is renting and this proportion is even higher in several OECD countries. ${ }^{3}$ The existence of a rental market with such significant amplitude impacts agents' arbitrages and housing decisions at an aggregate

\footnotetext{
${ }^{1}$ This is also particularly surprising in light of past evidence: Wong (42) provides empirical evidence on a decline of house prices in Hong Kong following the outbreak of SARS. She finds both direct and indirect effects of the epidemic.

${ }^{2}$ Notice that in US trends are confirmed both at a suburban and urban level so that the phenomenon is of macroeconomic relevance. The fall in rent-price ratios has been remarkably strong in both cities and the countryside. Housing prices have risen significantly both in large cities and in suburban areas (the FRED data base reports house prices for large cities such as New York, San Francisco or Boston, among others). Rents have been decreasing more in cities than in suburban areas where they stagnated (see Bloomberg CityLab data). See also the empirical analysis of Zhao (43) for urban, suburban, and rural areas. In particular, he finds that nationwide stilyzed facts are unlikely driven by urban residents fleeing to the suburbs, as the changes in housing price, demand, and supply since April 2020 are of similar magnitudes across metropolitan, micropolitan, small-town, and rural areas.

${ }^{3}$ Home ownership rates in 2004 were for instance $69.5 \%$ in Australia, 51.6\% in Austria, 71.7\% in Belgium, 68.9\% in Canada, $51.6 \%$ in Denmark, $66.0 \%$ in Finland, 54.8\% in France, $41 \%$ in Germany, 67.9\% in Italy, $69.3 \%$ in Luxembourg, $55.4 \%$ in the Netherlands, $83.2 \%$ in Spain, $38.4 \%$ in Switzerland, $70.3 \%$ in UK. See Andrews and Caldera Sanchez (2)
} 
level. Despite this, a large share of recent macroeconomic models have assumed away the existence of rental markets for real estate.

Because of the strong link between trends in housing markets and mortgages, ${ }^{4}$ our model also accounts for credit markets. Starting from Iacoviello (24), a rich literature has remarked the importance of housing loans to explain housing and business cycle fluctuations (see for instance Guerrieri and Iacoviello (18), Ferrero (15), Iacoviello and Neri (25), Justiniano et al. (29) among many others). The benchmark structure of these models allows to take into account the realistic feature that a significant share of the population has debt linked to real estate. Households' arbitrages need thus to account for the fact that housing also acts as a collateral and that its price fluctuations have implications for credit access. This approach has also the advantage to focus accurately on the "intensive margin" impact of households' individual decisions. It shows that the introduction of collateral constraints allows to generate amplification mechanisms and correlations, which help explain some key empirical facts. However, in general, this macroeconomic literature does not explicitly account for rental markets.

As real estate represents households' main wealth holdings, several contributions have focused on life-cycle portfolio facts (see Davis and Van Nieuwerburgh (11) for a review). In this literature, assumptions on prices vary ${ }^{5}$ but earnings are in general exogenous. Sommer et al. (39) contribute to it by incorporating households decisions about rental property into a model studying housing prices and rents. ${ }^{6}$ The equilibrium of this model is the result of the interaction of heterogeneous agents à la Aiyagari-Bewley-Huggett in a stochastic environment with incomplete markets. Their model focuses thus on the "extensive margin" impact of househods' decisions on the housing market. In such a framework, both interest rates and incomes are assumed to be exogenous. In a similar framework, Kiyotaki et al. (31) study the implications of an unexpected increase in the land's share of housing for the life-cycle wealth distribution and the relationship between housing prices and rents. Also, Favilukis et al. (14) use a general-equilibrium business-cycle model to study the

\footnotetext{
${ }^{4}$ Among many others, Favara and Imbs (13) emphasize the importance of introducing debt while studying housing dynamics.

${ }^{5}$ In Iacoviello and Pavan (26) prices are assumed to be exogenous.

${ }^{6}$ See also Sommer et al. Sommer et al. (40) for an analysis on housing policies in a similar framework.
} 
impact of risk on rent-prices dynamics and wealth distribution in response to credit shocks. In their model, rental markets are however exogenous. More recently, Kaplan et al. (30) explicitly account for rental markets to study the role of beliefs in explaining the housing bust during the Great Recession. ${ }^{7}$

In this paper, we study housing market fluctuations in a model à la Iacoviello (24) by incorporating both collateral constraints and rental markets. Our first contribution is theoretical, in that we demonstrate how it is possible to introduce a partition in the population. The population is eventually made of three types of agents: i) a landlord willing to rent housing and lend funds to other agents; ii) an homeowner who is subject to a collateral constraint limiting his access to credit to buy housing and iii) renters. Our aproach allows us to have a general equilibrium model where all aggregates and prices are determined endogenously. In the spirit of Favilukis et al (14), we highlight a relationship between rent-price ratios, housing prices and (bonds and credit) interest rates returns.

We then contribute to the literature by estimating the model with Bayesian techniques, in the spirit of Iacoviello and Neri (25). ${ }^{8}$ This allows us to calibrate our model realistically and then simulate it using standard perturbation methods. ${ }^{9}$ We believe that our framework is particularly useful to understand the joint dynamics of prices and aggregates in the housing market. We also study the behavior of the model under standard macroeconomic shocks, and provide explanations on the main mechanisms at work. We also show how our estimated model does a good job in matching standard moments of the macroeconomic aggregates as well as key variables of housing markets. Since now a smaller share of agents is debt constrained - because of rental markets - the model provides also a relatively good match of debt dynamics, without the need of introducing occasionally binding

\footnotetext{
${ }^{7}$ Search and matching frictions are also used to track flows from renting to home ownership and explain housing price fluctuations. However, while focusing on housing quality features, this literature abstracts from credit markets (see Ngai and Tenreyro (36) among many others).

${ }^{8}$ Differently from them, our estimation also accounts for rental markets and uses data including the Great Recession.

${ }^{9} \mathrm{~A}$ key advantage of our simple model is that it is easily solved with usual perturbation methods. In particular, other models which feature a rental market (see for instance Kiyotaki et al. (31) among many others) are usually solved with global methods. Due to the curse of dimensionality, the number of predetermined variables has to be limited, potentially leaving aside important aspects.
} 
constraints (for a discussion, see Guerrieri and Iacoviello (18)).

We finally argue that our simple model possesses all salient features necessary to explain current trends in housing markets. Our model allows indeed to highlight a strong and positive relationship linking rent-price ratios, interest rates and house prices (i.e., the counterpart of a standard equation defining the user cost of capital), which is intrinsic to the structure of our model. It explains how current dynamics are mainly the result of the transmission of policies implemented in response to the Covid-pandemic to housing markets. The restrictions in response to the pandemic have indeed imposed strong limits to current non-durable consumption but allowed consumption for durables and durable investment and triggered a surge in personal saving. We proxy the resulting change in behaviors by a shock ${ }^{10}$ on intertemporal preferences. This entails in our model both a decrease in interest rates and an increase in saving, consistently with data. We show how the shock propagates throughout the housing market so as to reproduce current trends on housing. In response to lower interest rates, because of the collateral constraint, the fall in credit costs entails a strong increase in house prices. Indeed, low interest rates dampen credit costs and allow to have access to more real estate - therefore raising house prices. However, because of the strong and positive relationship between interest rates, house prices and rents, a decrease in interest rates -pushing up house pricesneeds to be compensated by a large decrease in rents. The relationship between interest rates and rents featuring our model is key to match current trends and is consistent with the empirical evidence on the linkage between monetary policies and rents provided by Dias and Duarte (12). It also highlights how low interest rates push down rents. This is the result of the intertemporal arbitrage of landlords that shifts in favor of supplying more real estate to rent, which explains in turn the fall in rents and rent-price ratios.

Our analysis allows us to focus on the transmission channels- which are specific to housing markets - of Covid-induced policies and their different effects on heterogeneous households. Contrarily to the current view, it suggests that policies in response to the pandemic tend to drive down the welfare of housing-richest households (i.e., here landlords) through the effect on housing markets.

\footnotetext{
${ }^{10}$ We also analyze the effect of a standard intra-temporal shock on preferences à la Iacoviello (24) and other standard shocks in this literature.
} 
This result should eventually not surprise the reader and is consistent with previous evidence. ${ }^{11}$ Indeed, landlords' revenues are dampened by low interest rates and falling rental returns. While these developments do not significantly affect renters, they seem to benefit indebted house buyers - because of the fall of credit costs. In fact, after been dramatically affected by the financial crisis, indebted households are currently the winners of the low interest policy implied by the Covid pandemics.

This paper is organized as follows. Section 2 introduces a simplified version of the model and provides a proof for agents' partition together with the main intuitions. Section 3 presents the full model. The estimation and the ability of the model to match data are discussed in section 4 . Section 5 analyzes the dynamic properties of the model and section 6 current trends in housing markets. Section 7 concludes.

\section{A simple model model with housing rental}

In this section, we show how it is possible to introduce a partition of the population where renters and indebted homeowners coexist and collateral constraints are binding. Indeed, as remarked by d'Albis and Iliopulos (9), the standard framework of Iacoviello (24) assumes away rental markets. ${ }^{12}$ To provide an intuitive explanation of the main mechanism, we first introduce a simple endowment economy. In what follows we will then enrich this framework so as to account for for empirically relevant features.

We consider a $N$-agents population, indexed by $i=1, \ldots, N$. Each agent is assumed to be an expected-utility maximizer over an infinite lifespan and faces at date $t$ a problem that can be

\footnotetext{
${ }^{11}$ See Hohberger et al. (23), and Coibion et al. (8) who however do not account for wealth channels associated to housing.

${ }^{12}$ In fact, the introduction of rental markets entails some technical problems. When all variables are endogenously determined, the introduction of rental markets leads debt-constrained agents to rent in equilibrium so that collateral constraints are no more binding and become irrelevant.
} 
written as follows:

$$
\begin{aligned}
& \max _{\left\{c_{i t}, x_{i t}, h_{i t}, z_{i t}, d_{i t}\right\}} u_{i}\left(c_{i t}, h s_{i t}\right)+\mathbb{E}_{t} \sum_{j=1}^{\infty} \prod_{\varphi=1}^{j} \beta_{i t+\varphi} u_{i}\left(c_{i t+j}, h s_{i t+j}\right) \\
& \text { s.t. } \\
& h s_{i t}=h_{i t} x_{i t-1}+\phi z_{i t}, \\
& y_{i t}+d_{i t}+p_{t}\left(1-\delta_{x}\right) x_{i t-1}+p_{t} l_{t}\left(1-h_{i t}\right) x_{i t-1} \\
& =c_{i t}+R_{t-1} d_{i t-1}+p_{t} x_{i t}+p_{t} l_{t} z_{i t}, \\
& d_{i t} \leq m\left(1-\delta_{x}\right) x_{i t} \mathbb{E}_{t} p_{t+1}, \\
& x_{i t} \geq 0, z_{i t} \geq 0, c_{i t} \geq 0,0 \leq h_{i t} \leq 1 \\
& x_{i t-1} \text { given, } d_{i t-1} \text { given. }
\end{aligned}
$$

The utility $u_{i}$ of agent $i$ is a function of the consumption of non-durable goods, $c_{i t}$, and housing services, $h s_{i t}$. We assume that the utility is increasing and concave in both arguments and that marginal utilities tend to infinity when the argument equals zero. The time discount of each agent is stochastic and denoted $\beta_{i t}$. In this general framework we do not take a stand on the precise stochastic process defining $\beta_{i t}$ as we will specify it in what follows. For the moment we just need to assume that for all $t$, it satisfies : $1>\beta_{1 t}>\beta_{2 t}>\ldots>\beta_{N t}>0$. The agent characterized by $\beta_{1 t}$ is called the "dominant consumer", as his discount factor determines the equilibrium interest rate (see Becker and Foias (3)).

The first constraint shows that housing services can be consumed in two ways. Either agent $i$ has inherited some housing, $x_{i t-1}$, from period $t-1$, in which case she can decide to own-occupy a share $h_{i t} \in[0,1]$ of it and rent a share $1-h_{i t}$ to other agents. She can also decide to rent housing services $\phi z_{i t}$ from other agents with $\phi \in(0,1) .{ }^{13}$ As $\phi<1$, an agent who would decide to rent $z_{i t}$ units of housing to another agent would only transfer $\phi z_{i t}<z_{i t}$ units of housing services to this agent. ${ }^{14}$ We thus interpret $\phi<1$ as implying that the rental market is imperfect in the sense that rented units are imperfect substitutes to owned ones. We do not model the source of this imperfection which

\footnotetext{
${ }^{13}$ Limit cases are studied in the literature. The case with $\phi=1$ corresponds to a perfect rental market studied by d'Albis and Iliopulos (9). The case with $\phi=0$ corresponds to the standard setting with no rental market, as in Iacoviello (24). We exclude them here to reduce the length of the proofs.

${ }^{14}(1-\phi)$ is akin to an iceberg transport cost as is often considered in the trade literature.
} 
could stem from tenants' limited discretion over the way the house is used or modified, preferential tax treatments for housing or rental premiums resulting from moral hazard (see e.g. Henderson and Ioannides (21)). ${ }^{15}$

The second constraint in problem (1) is the budget constraint faced by agent $i$. She receives an exogenous income $y_{i t}>0$, can borrow $d_{i t}$ from other agents, resells the depreciated housing she owns $\left(1-\delta_{x}\right) x_{i t-1}$ at price $p_{t}$, where this latter is the price for housing (the relative price of housing in terms of the consumption good, who is set as the numeraire) and receives income $p_{t} l_{t}\left(1-h_{i t}\right) x_{i t-1}$ from the housing she rents, where $p_{t} l_{t}$ is the rent paid by renters, and $l_{t}$ is the rent-to-price or rentprice ratio. ${ }^{16}$. Those funds can be used to purchase consumption goods $c_{i t}$, repay debt $R_{t-1} d_{i t-1}$ (where $R_{t-1}$ is the gross real interest rate set in $t-1$ ), purchase new housing $x_{i t}$ at price $p_{t}$ and pay for the $z_{i t}$ rented units of housing.

The third constraint is a standard collateral constraint. It states that debt $d_{i t}$ of agent $i$ cannot be larger than a share $m \in(0,1)$ of the expected value of the net-of-depreciation housing stock $\left(1-\delta_{x}\right) x_{i t}$ she owns, with $\delta_{x} \in[0,1)$. The collateral constraint can be justified by enforcement problems (see Kiyotaki and Moore (32)). We finally mention that owned housing, rented housing and consumption cannot be negative.

Propositions 1 and 2 characterize the partition of the population of our model.

Proposition 1. There are three types of agents in the economy: tenants, defined such that $x_{i t}=0$ and $z_{i t}>0$, owner-occupiers, defined such that $x_{i t}>0$ and $h_{i t}=1$, and landlords, defined such that $x_{i t}>0, h_{i t} \in(0,1)$ and $z_{i t}=0$.

Proof. See Appendix A.

Proposition 1 establishes that in equilibrium the population of our economy is composed by three types of agents only: i) tenants, who do not own the housing they live in; ii) owner-occupiers, who

\footnotetext{
${ }^{15}$ Several papers allow for $\phi<1$ within life-cycle frameworks as Kiyotaki et al. (31) and Iacoviello and Pavan (26). The novelty of the analysis here is to show that in a framework with infinitely-lived agents $\phi<1$ can lead to an economy with both renters and indebted homeowners.

${ }^{16}$ Notice, however that, because of the imperfection in the rental market, the effective rent paid by a renter for one unit of housing services is $p_{t} l_{t} / \phi>p_{t} l_{t}$.
} 
occupy all the housing they own and iii) landlords, who live in a share of their housing and rent the rest. All other possibilities are ruled out as they are suboptimal. ${ }^{17}$ We now characterize the partition by focusing on the steady state.

Proposition 2. At the deterministic steady state, the dominant consumer is the only landlord. She lends funds to owner-occupiers till their borrowing limit and rents some housing to tenants. There exists a unique $\bar{\beta}_{i} \in\left(0, \beta_{1}\right)$ such that all agents with a $\beta_{i}<\bar{\beta}_{i}$ are tenants and all agents with a $\beta_{i}<\left[\bar{\beta}_{i}, \beta_{1}\right)$ are owner-occupiers.

Proof. See Appendix A.

Proposition 2 shows how the partition of the population around the steady state depends on discount-rate values. In particular, only the agent with the highest discount rate is a landlord. There is also a set of agents with lower discount rates who are owner-occupiers, while those with the lowest discount rates are tenants. This result generalizes the setting of Becker and Foias (3) to an economy with housing and rental.

To understand the intuition behind this result notice that if there were no rental markets, the dominant consumer would lend funds to the less patient ones - who would in turn use them to purchase housing. As the collateral constraint is linked to a down-payment, less patient consumers would still be net savers because the value of their homes would exceed the value of their debt. Introducing a rental market offers another way for less patient consumers to buy housing services. One possibility is to borrow and purchase the houses they occupy. However, this comes at the cost of having positive net savings. ${ }^{18}$ The other possibility is to rent housing and have zero net savings. However, because the parameter $\phi$ is lower than one, renting housing services is also costly. There is thus a trade-off. The above proposition implies that relatively patient consumers favor the first option: they have indeed a lower opportunity cost of having positive net savings. In contrast, very

\footnotetext{
${ }^{17}$ The benchmark model in what follows will be based on this partition and borrow from data the shares of the different types of agents.

${ }^{18}$ In equilibrium, the collateral constraint is binding and the interest rate is set by the dominant consumer. Indebted agents would thus choose to borrow more (i.e. save less) in the absence of down-payment requirements.
} 
impatient consumers prefer renting despite the fact that it is relatively costly because of a greater opportunity cost of saving.

Proposition 2 shows that a partition of landlords, owner-occupiers and tenants can be obtained in a model with agents having infinite lifespans, because of discount factor heterogeneity. It implies that a rental market can exist, alongside with indebted homeowners, even without resorting to an overlapping-generations structure with finite lifespans. ${ }^{19}$ This allows to study rental markets within standard business cycle model where all variables of interest are endogenous.

\section{$2.1 \quad$ Returns}

We now focus our attention on returns because they represent the link between finance and the housing market. In general equilibrium, housing returns and bonds returns need indeed to be equalized. Proposition 3 shows how interest rates are structurally linked to house prices and rentprice ratios.

Proposition 3. In the neighborhood of the deterministic steady state, housing prices, rents and interest rates are linked by the following relationship:

$$
R_{t}=\mathbb{E}_{t} \frac{p_{t+1}}{p_{t}}\left[\left(1-\delta_{x}\right)+l_{t+1}\right] \varepsilon_{t+1}
$$

where:

$$
\varepsilon_{t+1}:=\frac{\beta_{1 t+1} u_{c_{1 t+1}}^{\prime}}{\mathbb{E}_{t} \beta_{1 t+1} u_{c_{1 t+1}}^{\prime}} .
$$

Proof. See Appendix A.

In the absence of uncertainty, $\varepsilon_{t+1}=1$, and equation (2) is a standard arbitrage equation. It equates the gross interest rates on bonds to the return of an unit of non-depreciated housing ${ }^{20}$. In the presence of stochastic shocks, the gap between the expected and the realized discounted

\footnotetext{
${ }^{19}$ Iacoviello and Pavan (26) among many others introduce rental markets in a overlapping generation (OLG) model. The OLG framework allows to study other interesting features, that are however beyond the scope of this work.

${ }^{20}$ Notice that $l_{t+1}$ is the counterpart of the traditional formula defining the user cost of capital.
} 
utility of the most patient agent (i.e., the dominant consumer in Becker and Foias (3)) influences the relation. Indeed, risk and volatility can affect the nature of the relationship between interest rates, house price dynamics and rent-price ratios.

Equation (2) has similar counterparts in the literature and, most notably, refers to the definition of housing returns in Favilukis et al. (14) - once accounting for the housing premium between bond rates and housing returns. However, as Favilukis et al. do not explicitly model rental markets, the term $l_{t+1}$ is replaced in their work by a marginal utility ratio (marginal utility of housing services over marginal utility of consumption), which is the result of a weighted average of the population's marginal utilities and accounts for a weighted average of discount factors. The wealth distribution of the population is key in their article as it determines risk sharing and risk premia. In contrast, in our work both $l_{t+1}$ and $\varepsilon_{t+1}$ are a function of marginal utilities of the dominant consumer only. The latter also pins down both interest rates and rents. ${ }^{21}$ Notice in particular that the arbitrage equation itself is pinned down by the dominant consumer. Indeed, the landlord is the only agent who is an active player on the i) credit market, ii) the real-estate market and the iii) rental market. ${ }^{22}$ Therefore, the equilibrium is imposed by the portfolio arbitrage of agents of type 1 .

\section{The full model}

The results of the previous section have shown that it is possible to introduce an explicit rental market in a framework with infinitely-lived agents if there is heterogeneity in discount factors. We now use these insights to study the dynamics of housing and rental markets in a standard business cycle model.

To do so, we enrich the above endowment economy in order to account for several empirically realistic features. In later sections, we assess the ability of our full model to match various aggregate

\footnotetext{
${ }^{21}$ This is consistent with the main mechanism in Kaplan et al. (30), where non-constrained house owners play a key role in housing markets dynamics.

${ }^{22}$ We remind the reader that Proposition 1 and 2 imply that in equilibrium agents of type 2 do participate to the credit market and the real estate market but are not players of the rental market. In contrast, agents of type 3 do not access credit nor real estate markets but are active players of rental markets.
} 
moments. Our model features two productions sectors $s=\{c, h\}$ where $c$ refers to consumption goods and $h$ to housing goods, respectively. We assume that the economy is inhabited by the three types of representative agents following Proposition 1: landlords, owner-occupiers and tenants. The economy is hit by a set of stochastic shocks which are standard in the macroeconomic literature on housing.

\subsection{Households}

The model features three different types of agents, who are indexed by $i=1,2,3$. Each type of agent has a different time-preference parameter: as of date 0 , agent $i$ discounts date $t$ with $\beta_{i}^{t} \tilde{\beta}_{t} / \tilde{\beta}_{0}$, where $\beta_{i}$ satisfies $1>\beta_{1}>\beta_{2}>\beta_{3}>0$. Agents 1 (characterized by $\beta_{1}$ ), are the most patient ones and are thus landlords while agents 2 and 3 are respectively owner-occupiers and renters. As in Guerrieri and Iacoviello (18), $\tilde{\beta}_{t}$ is a random variable that captures shocks to intertemporal preferences and satisfies:

$$
\log \tilde{\beta}_{t}=\rho_{\beta} \log \tilde{\beta}_{t-1}+\epsilon_{\beta t} .
$$

Discount-rates shocks are nowadays very common in the macroeconomic literature ${ }^{23}$ We allow the population of each type to be of different size, so as to match empirical evidence. The size of the population of agents 1 is used as a normalizer and is set to 1 . We then denote by $\omega_{2}>0$ and $\omega_{3} \Omega_{t}>0$ the relative shares of agents of type 2 and 3 with respect to the one of type $1 . \Omega_{t}$ is a random variable that captures shocks to the proportion of renters in the population. It satisfies:

$$
\log \Omega_{t}=\rho_{\Omega} \log \Omega_{t-1}-\epsilon_{\Omega t}
$$

The home-ownership rate at time $t$ is thus defined according to agents' population shares as $(1+$ $\left.\omega_{2}\right) /\left(1+\omega_{2}+\omega_{3} \Omega_{t}\right)$, and the share of landlords among homeowners is $1 /\left(1+\omega_{2}\right)$.

Let us first consider the individual problem for agents 1 , who are the landlords and the only ones willing to save in equilibrium (see Propositions 1 and 2). They are thus the sole owners of both the

\footnotetext{
${ }^{23}$ See also the macroeconomic literature studying the dynamics around the zero lower bound, where they have been extensively used. We can also interpret them here as a way to mimic the effect of monetary policies - which are otherwise not modeled here.
} 
capital stocks and land. The expected utility of these agents is:

$$
\mathbb{E}_{0} \sum_{t=0}^{\infty} \beta_{1}^{t} \tilde{\beta}_{t}\left[\ln c_{1 t}+j_{t} \ln \left(h_{t} x_{1 t-1}\right)-\chi_{1} \frac{n_{1 t}^{\eta}}{\eta}\right],
$$

where $c_{1 t}$ is the consumption of non-durables, $h_{t} x_{1 t-1}$ is the consumption of housing services and $n_{1 t}$ is hours worked. Agent 1 owns $x_{1 t-1}$ units of housing but rents a share $\left(1-h_{t}\right)$ of this housing stock to other agents, thus effectively consuming $h_{t} x_{1 t-1}$ units of housing services. The parameter $\eta>1$ determines the elasticity of labor supply, while the parameter $\chi_{1}>0$ captures the preference for leisure. ${ }^{24}$ As in Iacoviello (24), we allow for shocks to housing preferences, $j_{t}$, with:

$$
\log j_{t}=\rho_{j} \log j_{t-1}+\left(1-\rho_{j}\right) \log j_{s s}+\epsilon_{j t}
$$

where $j_{s s}>0$ is the steady-state value of $j_{t}$ and where $\epsilon_{j t}$ is a shock correlated to $\epsilon_{\Omega t}$. The increase in the demand for housing is thus correlated to the increase of the share of homeowners.

The budget constraint of agents 1 is:

$$
\begin{gathered}
p_{t}\left[\left(1-\delta_{x}\right)+l_{t}\left(1-h_{t}\right)\right] x_{1 t-1}+r_{t}^{c} k_{t-1}^{c}+r_{t}^{h} k_{t-1}^{h}+p_{t}^{q}\left(1+l_{t}^{q}\right) q_{t-1} \\
+d_{1 t}+w_{t} n_{1 t}=c_{1 t}+R_{t-1}^{d} d_{1 t-1}+i_{t}^{c}+i_{t}^{h}+p_{t} x_{1 t}+p_{t}^{q} q_{t}+\frac{\phi_{x} p_{t}\left(x_{1 t}-x_{1 t-1}\right)^{2}}{2} .
\end{gathered}
$$

The left-hand side of the equation corresponds to the resources of an agent of type 1 . They are the sum of: the value of the previous-period housing stock, $p_{t}\left(1-\delta_{x}\right) x_{1 t-1}$, where $p_{t}$ is the housing price and $\delta_{x} \in[0,1]$ the depreciation rate of housing; the rent received on the $\left(1-h_{t}\right)$ share of rented units, where $l_{t}$ is the rent-price ratio; the returns on investments in the two sectors, $r_{t}^{s} k_{t-1}^{s}$, where $r_{t}^{s}$ is the rental price of capital of sector $s$ and $k_{t-1}^{s}$ is the capital invested in sector $s$; the value of the land owned by agent $1, p_{t}^{q} q_{t-1}$, where $p_{t}^{q}$ is the price and $q_{t-1}$ the quantity; the rent received from the land, $p_{t}^{q}\left(1+l_{t}^{q}\right) q_{t-1}$, where $l_{t}^{q}$ is the rent-price ratio for the land; new debt/credit, $d_{1 t}$ (as discussed above, agent 1 is always a lender in equilibrium, which implies $d_{1 t}<0$ ); labor income, $w_{t} n_{1 t}$, where $w_{t}$ is the wage. The right-hand side of (8) represents expenditures. They include consumption of non-durables, the payment of the debt interests at rate $R_{t-1}^{d}$, investments

\footnotetext{
${ }^{24}$ This formulation of the flow utility follows Iacoviello (24).
} 
in capital stock of both sectors, $i_{t}^{s}$, the purchases of housing and land, and housing adjustment costs as in Silos (38) - with $\phi_{x} \geq 0$ as a measure of the inefficiency.

Land does not depreciate and its quantity is constant and normalized to 1 (as commonly assumed in the literature). It effectively acts as an adjustment cost which can increase the volatility of house prices (see, for instance, Iacoviello and Neri (25)). Capital in both sectors depreciates at rate $\delta_{s} \in[0,1]$. Investments in those sectors are affected by efficiency shocks as in Christiano et al. (5), which are denoted $\Upsilon_{t}^{s}$ and satisfy:

$$
\log \Upsilon_{t}^{s}=\rho \Upsilon^{s} \log \Upsilon_{t-1}^{s}+\epsilon \Upsilon^{s} t
$$

Moreover, we introduce adjustment costs (as e.g. in Justiniano et al. (27), Christiano et al. (6) or Guerrieri and Iacoviello (18)), so that capital accumulation in sector $s$ follows:

$$
k_{t}^{s}=\Upsilon_{t}^{s} i_{t}^{s}\left[1-\frac{\phi_{s}}{2}\left(\frac{i_{t}^{s}}{i_{t-1}^{s}}-1\right)^{2}\right]+\left(1-\delta_{s}\right) k_{t-1}^{s},
$$

where $\phi_{s} \geq 0$ gives the intensity of the inefficiency. As a result of these adjustment costs, the relative price of capital fluctuates.

The problem of agents 1 is to maximize (6) subject to (8) and (10) given $\left(x_{1 t-1}, k_{t-1}^{c}, k_{t-1}^{h}, q_{t-1}, d_{1 t-1}\right)$. The full list of first order conditions can be found in Appendix B.1.

Let us now consider the individual problem of agents 2. Following the previous theoretical results, we consider that $\beta_{2}$ is such that, in equilibrium, these agents are owner-occupiers who borrow up to the limit set by the collateral constraint, and who do not hold any assets except housing (which serves as a collateral for loans). For simplicity, variables referring to agents 2 and 3 are defined as the ones for agents 1 but are indexed by 2 and 3 respectively. Expected utility for these agents is given by:

$$
\mathbb{E}_{0} \sum_{t=0}^{\infty} \beta_{2}^{t} \tilde{\beta}_{t}\left[\ln c_{2 t}+j_{t} \ln x_{2 t-1}-\chi_{2} \frac{n_{2 t}^{\eta}}{\eta}\right]
$$


with the budget constraint given by:

$$
p_{t}\left(1-\delta_{x}\right) x_{2 t-1}+d_{2 t}+w_{t} n_{2 t}=c_{2 t}+R_{t-1}^{d} d_{2 t-1}+p_{t} x_{2 t}+\frac{\phi_{x} p_{t}\left(x_{2 t}-x_{2 t-1}\right)^{2}}{2} .
$$

As in (1), the collateral constraint writes:

$$
d_{2 t} \leq m\left(1-\delta_{x}\right) x_{2 t} \mathbb{E}_{t} p_{t+1},
$$

where $m>0$ is given. ${ }^{25}$ Following Proposition 2, the constraint in (13) is binding. The problem of agent 2 consists in maximizing (11) subject to (12) and (13) for $\left(x_{2 t-1}, d_{2 t-1}\right)$ given. The full list of first order conditions can be found in Appendix B.2.

Let us finally consider agents 3 . Following our theoretical results, we assume that $\beta_{3}$ is such that these agents are renters in equilibrium, and therefore hold no assets. Their expected utility writes:

$$
\mathbb{E}_{0} \sum_{t=0}^{\infty} \beta_{3}^{t} \tilde{\beta}_{t}\left[\ln c_{3 t}+j \ln \left(\phi z_{3 t}\right)-\chi_{3} \frac{n_{3 t}^{\eta}}{\eta}\right]
$$

where $z_{3 t}$ is the amount of housing rented by this agent and $\phi$ is kept for consistency with problem (1). We also assume that preference shocks for housing only affect homeowners, so that for agents $3 j=j_{s s}{ }^{26}$

The budget constraint applying to agents 3 is:

$$
w_{t} n_{3 t}=c_{3 t}+p_{t} l_{t} z_{t}
$$

Note that, since agents 3 hold no assets, their problem is static. ${ }^{27}$

\footnotetext{
${ }^{25}$ Following Iacoviello and Neri (25), we choose not to incorporate LTV shocks into our baseline model. This is because LTV shocks contribute little to match house price fluctuations and generate too much debt volatility. There is not clear consensus in the literature on the role played by LTV shocks. Several works suggest that shocks hitting collateral constraints are not key drivers of housing markets dynamics (e.g Justiniano et al. (29), Kiyotaki et al. (31) or Sommer et al. (39)). In contrast, Favilukis et al. (14) and Garriga et al. (17) LTV shocks are main drivers of housing dynamics. Having said that, Kaplan et al. (30) stress how the presence of a rental market implies that fewer agents are credit-constrained, which limits the effects of collateral shocks. We borrow thus their view and provide a robustness check with a version of our model with LTV shocks in the Appendix.

${ }^{26}$ The preference shock we consider is a preference shock for owned housing units, as it is commonly assumed in the housing literature.

${ }^{27}$ Their optimal choices are thus not influenced by the specific value of $\beta_{3}$, that determines instead the fact that they are renters in equilibrium (see Proposition 2 and the way the above problem is specified). First order conditions are presented in Appendix B.3.
} 


\subsection{Firms}

Firms produce in a perfectly competitive environment. As mentioned above, there are two sectors that produce non durable goods and housing, respectively. The production function of the firms of the consumption sector is given by: $Y_{c t}=A_{c t} K_{c t}^{\gamma_{c}} L_{c t}^{\alpha_{c}}\left(\right.$ with $\gamma_{c}+\alpha_{c}=1$ ), where $K_{c t}$ and $L_{c t}$ are respectively the capital and labor used by the firms and $A_{c t}$ is an exogenous productivity factor specific to the consumption sector, which satisfies:

$$
\log A_{c t}=\rho_{A_{c}} \log A_{c t-1}+\epsilon_{A c t} .
$$

The production function of the firms of the housing sector is given by: $Y_{h t}=A_{h t} K_{h t}^{\gamma_{h}} L_{h t}^{\alpha_{h}} Q_{t}^{1-\alpha_{h}-\gamma_{h}}$ where $K_{h t}, L_{h t}$ and $Q_{t}$ are respectively capital, labor and land used by the firm (see e.g. Iacoviello and Neri (25)) and $A_{h t}$ is a productivity factor, which satisfies:

$$
\log A_{h t}=\rho_{A_{h}} \log A_{h t-1}+\epsilon_{A h t} .
$$

where we allow $\epsilon_{A h t}$ to be correlated with $\epsilon_{A c t}$. First order conditions of the firms problem are derived in Appendix B.4.

\subsection{Equilibrium}

There are 8 markets in the economy, which clear in equilibrium. Let us start with asset markets. Equilibrium in the capital markets for both sectors implies: $K_{c t}=k_{t-1}^{c}$ and $K_{h t}=k_{t-1}^{h}$. The equilibrium in the market for land is $Q_{t}=q_{t-1}=1$, and the one for debt is $d_{1 t}+\omega_{2} d_{2 t}=0$. Moreover, the rental market for housing satisfies: $\omega_{3} \Omega_{t} z_{3 t}=\left(1-h_{t}\right) x_{1 t-1}$.

As we assume that labor is perfectly mobile across sectors, the equilibrium condition for the labor market is:

$$
L_{h t}+L_{c t}=n_{1 t}+\omega_{2} n_{2 t}+\omega_{3} \Omega_{t} n_{3 t} .
$$

We now turn to the equilibrium for our two goods markets. The equilibrium condition for the non 
durable goods is:

$$
\begin{aligned}
Y_{c t}= & c_{1 t}+\omega_{2} c_{2 t}+\omega_{3} \Omega_{t} c_{3 t}+i_{t}^{c}+i_{t}^{h} \\
& +\frac{\phi_{x} p_{t}\left(x_{1 t}-x_{1 t-1}\right)^{2}}{2}+\omega_{2} \frac{\phi_{x} p_{t}\left(x_{2 t}-x_{2 t-1}\right)^{2}}{2},
\end{aligned}
$$

while the equilibrium for the housing good writes:

$$
Y_{h t}=x_{1 t}+\omega_{2} x_{2 t}-\left(1-\delta_{x}\right)\left[x_{1 t-1}+\omega_{2} x_{2 t-1}\right] .
$$

In the next section, we discuss our procedure to calibrate and estimate the model.

\section{Model versus data}

\subsection{Data}

We estimate our model using series for the following variables, which are crucial for housing markets: house prices, the rent-price ratio, consumption, non-residential (i.e. capital) investment, residential investment, private debt, interest rates and homeownership rates. GDP is not included as it is the sum of residential investment (multiplied by house prices) and output in the rest of the economy. ${ }^{28}$ We estimate our model from 1965 to $2016^{29}$ with quarterly logged HP-filtered data (the smoothing coefficient is 1600). Following Pfeifer (37), we use a one-sided HP-filter. ${ }^{30}$ For robustness, we repeat the exercise for the period 1965 to 2006. The latter period has the advantage of excluding the years of the Great Recession and thus significant non-linearities in housing markets such as the zero-lower bound for interest rates, and significant variations in house prices and debt.

The choice of our data follows closely Iacoviello and Neri (25) and is detailed in Appendix C. Figure 1 shows the series (in levels) used for the estimation.

\footnotetext{
${ }^{28}$ Note that residential investment is the output of the housing sector.

${ }^{29}$ This is the longest period for which we dispose of complete series.

${ }^{30}$ We use the matlab codes by Meyer-Gohde (34) based on the procedure in Stock and Watson (41).
} 
Figure 1: Data
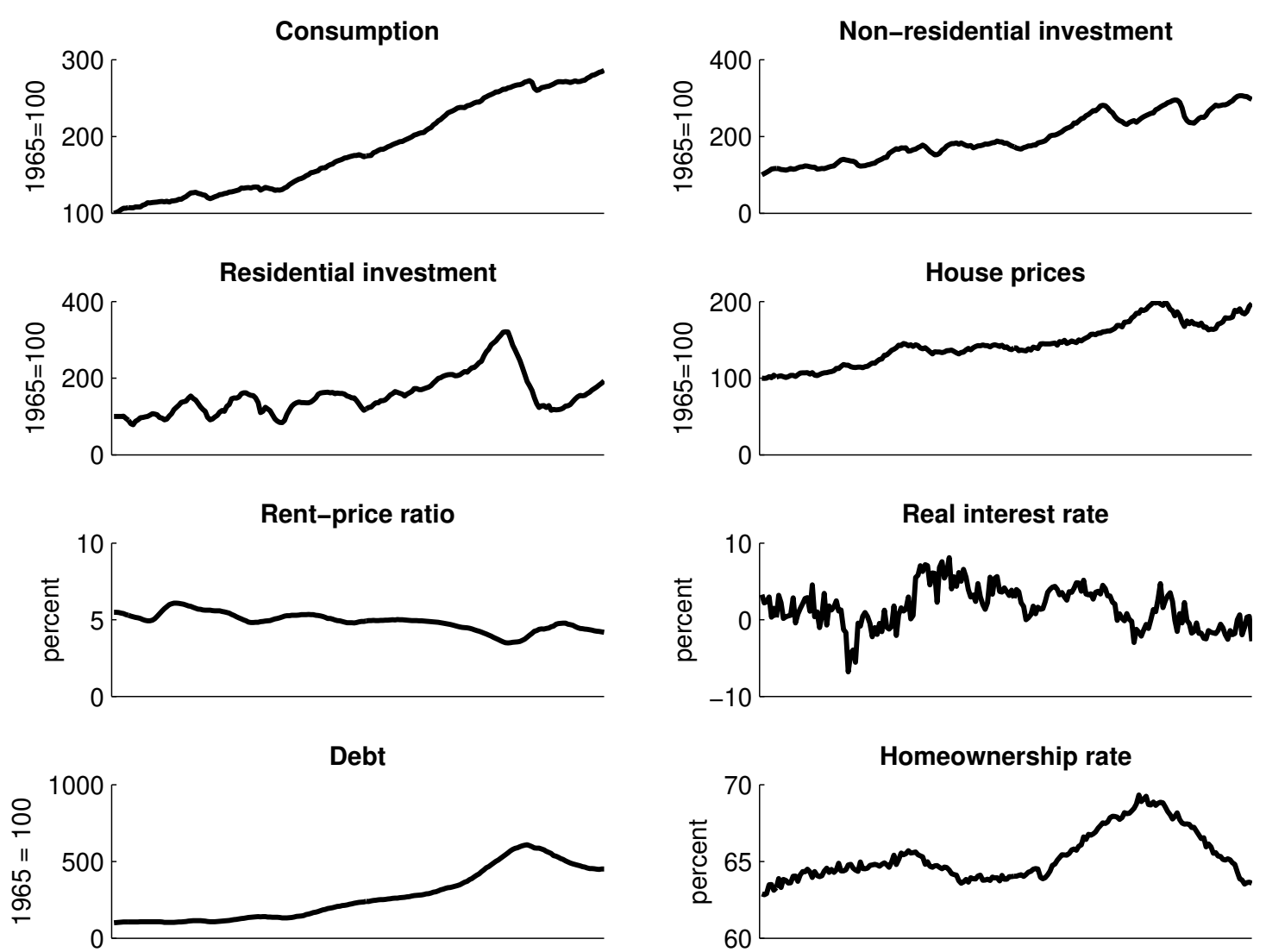

Notes: Data used for estimation. Period: 1965Q1-2016Q1. The plotted rent-price ratio and real interest rate are annualized.

\subsection{Parameters calibration}

We calibrate $\beta_{1}$ so that the annual real interest rate is $3 \%$ (as in Iacoviello and Neri (25) or Kaplan et al. (30)). $\beta_{2}$ is set to 0.98 in line with Hendricks (22) and $\beta_{3}$ can assume any value as it does not play any role in the equilibrium equations. The same applies to $\phi$. We only assume that $\beta_{3}$ and $\phi$ are low enough such that agent 3 is a renter in equilibrium (see Proposition 2). The steady-state value of the preference for housing, $j_{s s}$, is set to have a ratio of residential real estate over quarterly GDP of about 4 (its average between 1965 and 2016).

The parameters driving the preference for leisure $\chi_{1}, \chi_{2}$ and $\chi_{3}$ are set such that $n_{1}=n_{2}=n_{3}=$ $1 / 3$. The underlying assumption is that agents of different types spend the same amount of time working at the steady state. 
The relative shares $\omega_{2}$ and $\omega_{3}$ are calibrated to a have home ownership rate of $66.6 \%$ and so that landlords represent $10 \%$ of the homeowners, as in Sommer et al (39). This approach has the advantage of setting these parameters on clear empirical evidence without the need to use wealth holdings as a proxy, as in previous works in this literature. Indeed, wealth holdings data entail several measurement problems to calculate shares (see discussion in Justiniano et al. (28) among others).

The quantity of aggregate land is normalized to 1 . The parameter $\delta_{x}$ is such that the annual rentprice ratio is $4.9 \%$ (its average between 1965 and 2016). The corresponding annual depreciation rate for housing is about $1.8 \%$, which is close to micro estimates (e.g. Nakajima and Telyukova (35) use a value of $1.7 \%$ ). We set the loan-to-value ratio, $m$, to 0.85 as in Iacoviello and Neri (25), and in line with Calza et al. (4). ${ }^{31}$

We set $\gamma_{c}$ to 0.3 in line with the literature (e.g. Iacoviello (24)) and thus $\alpha_{c}$ is set to 0.7. Following Iacoviello and Neri (25), the shares of land and capital, $\gamma_{h}$, in the construction sector are both set to 0.1. The share of labor, $\alpha_{h}$, is thus 0.8 , in line with Iacoviello (24). Capital depreciation is assumed to be the same in both sectors and $\delta_{h}=\delta_{c}=0.0139$ in line with Davis and Heathcote (10). Table 1 summarizes the calibration.

\subsection{Parameters estimation}

We estimate the persistence and standard deviations of the shocks that hit our economy, as well as the adjustment costs for capital and housing.

Our list of shocks include the technology shock in the consumption and housing sector, respectively (see equation 16 and 17), the preference shock for housing (see 7), the discount factor shock (see 4), the home ownership shock (see 5) and efficiency shocks in both sectors (see 9).

Table 2 displays the priors and posteriors of the parameters we estimate. Our priors for the parame-

\footnotetext{
${ }^{31}$ This entails a steady state level of debt to quarterly GDP of about 1.45 , which is smaller than its average between 1965 and 2016 (a period which includes the high debt increases prior to the Great Recession), but still globally in line with data.
} 
Table 1: Calibrated parameters

\begin{tabular}{|c|c|c|}
\hline Parameters & Values & Source/Targets \\
\hline$\beta_{1}$ & 0.99264 & $3 \%$ annual interest rate, Iacoviello and Neri (25) \\
\hline$\beta_{2}$ & 0.98 & Hendricks (22) \\
\hline$\chi_{1}$ & 1.11 & $n_{1}=1 / 3$ \\
\hline$\chi_{2}$ & 3.20 & $n_{2}=1 / 3$ \\
\hline$\chi_{3}$ & 3.25 & $n_{3}=1 / 3$ \\
\hline$j$ & 0.07 & ratio residential real estate/ quarterly GDP $4 \%$ \\
\hline$\omega_{2}$ & 3.9204 & $10 \%$ of homeowners, Sommer et al. (39) \\
\hline$\omega_{3}$ & 2.2440 & $66 \%$ homeownership rate, Sommer et al. (39) \\
\hline$\gamma_{c}$ & 0.3 & Iacoviello (24) \\
\hline$\delta_{c}, \delta_{h}$ & 0.013925 & annual capital depreciation rate, Davis and Heathcote (10) \\
\hline$\alpha_{h}$ & 0.7 & labour in construction, Iacoviello and Neri (25) \\
\hline$\gamma_{h}$ & 0.1 & Iacoviello and Neri (25) \\
\hline$\delta_{x}$ & 0.0048 & annual rent price ratio of $4.9 \%$ \\
\hline$m$ & 0.85 & Iacoviello and Neri (25) \\
\hline
\end{tabular}


ters driving the adjustment costs for capital adjustment in the two sectors $\left(\phi_{c}\right.$ and $\left.\phi_{h}\right)$ are based on Iacoviello and Neri (25). We follow the logic of Silos (38) and choose the prior for adjustment costs of owned housing $\phi_{x}$ so as to make sure that the contemporaneous correlation between residential investment and output is positive. We eventually choose a mean value of 3 with a relatively large standard deviation of 2 .

As Iacoviello and Neri (25), the prior means and standard deviations of the persistence parameters are set to 0.8 and 0.1 , except for those related to the marginal efficiency of investment, which are set based on the priors used in Christiano et al. (5), and for those related to the shock affecting the proportion of renters. For the latter, we chose a moderate value of 0.5 for the prior mean, with a relatively large standard deviation of 0.2 .

Finally, we allow for a degree of correlation between the two productivity shocks and between the preference shock for owned housing units and the shock to the proportion of renters. We use diffuse priors for these correlations, with a prior mean of 0 .

The posterior distributions are estimated using the Metropolis-Hastings algorithm. ${ }^{32}$ Table 2 shows key statistics of these posterior distributions. In line with Iacoviello and Neri (25), we find that technological shocks in the consumption and housing sectors, respectively, are quite persistent, as well as preference shocks for owned housing. We also find that productivity innovations in the housing and consumption sector are positively correlated. As expected, housing preferences and the homeownership rate are also positively correlated.

We find a relatively high volatility for the shock on the marginal efficiency of investment in the housing sector, together with a relatively strong persistence. This is explained by a strong degree of volatility of residential investment observed in the data, to which the shock contributes significantly (see the analysis of moments and the one for the variance decomposition below).

Finally, we find that shocks to intertemporal preferences are not very persistent. This comes from the fact that the real interest rate displays significant short-run volatility (see figure 1).

\footnotetext{
${ }^{32}$ The model is solved and estimated using Dynare. For the estimation, we use a first-order approximation of the model around the deterministic steady state. Codes are available upon request.
} 
Table 2: Estimated parameters

\begin{tabular}{cccccc}
\hline & & \multicolumn{4}{c}{ Posterior } \\
\cline { 3 - 5 } Parameter & Prior [mean,std] & \multicolumn{4}{c}{} \\
\cline { 3 - 5 } & & Mean & Median & $10 \%$ & $90 \%$ \\
$\phi_{c}$ & gamma [10,2.5] & 5.568 & 5.402 & 4.323 & 7.040 \\
$\phi_{h}$ & gamma [10,2.5] & 12.719 & 12.638 & 9.688 & 15.853 \\
$\phi_{x}$ & gamma [3,2] & 4.204 & 4.174 & 2.976 & 5.431 \\
$\rho_{A_{c}}$ & beta [0.8,0.1] & 0.955 & 0.956 & 0.939 & 0.971 \\
$\rho_{A_{h}}$ & beta [0.8,0.1] & 0.917 & 0.917 & 0.871 & 0.965 \\
$\rho_{j}$ & beta [0.8,0.1] & 0.979 & 0.980 & 0.973 & 0.985 \\
$\rho_{\beta}$ & beta [0.8,0.1] & 0.390 & 0.390 & 0.338 & 0.440 \\
$\rho_{\Upsilon^{c}}$ & beta [0.5,0.2] & 0.406 & 0.407 & 0.332 & 0.478 \\
$\rho_{\Upsilon^{h}}$ & beta [0.5,0.2] & 0.996 & 0.996 & 0.992 & 0.998 \\
$\rho_{\Omega}$ & beta [0.5,0.2] & 0.689 & 0.688 & 0.626 & 0.755 \\
$\sigma_{A_{c}}$ & invgamma [0.001,0.1] & 0.007 & 0.007 & 0.006 & 0.007 \\
$\sigma_{A_{h}}$ & invgamma [0.001,0.1] & 0.013 & 0.013 & 0.013 & 0.014 \\
$\sigma_{j}$ & invgamma [0.001,0.1] & 0.031 & 0.031 & 0.029 & 0.033 \\
$\sigma_{\beta}$ & invgamma [0.001,0.1] & 0.005 & 0.005 & 0.005 & 0.006 \\
$\sigma_{\Upsilon^{c}}$ & invgamma [0.055,0.2] & 0.055 & 0.054 & 0.042 & 0.069 \\
$\sigma_{\Upsilon_{h}}$ & invgamma [0.055,0.2] & 0.270 & 0.270 & 0.243 & 0.298 \\
$\sigma_{\Omega}$ & invgamma [0.001,0.1] & 0.009 & 0.009 & 0.008 & 0.009 \\
$\operatorname{corr}\left(\epsilon_{A c}, \epsilon_{A h}\right)$ & beta [0.0,0.3] & 0.474 & 0.474 & 0.404 & 0.544 \\
$\operatorname{corr}\left(\epsilon_{j}, \epsilon_{\Omega}\right)$ & beta [0.0,0.3] & 0.243 & 0.245 & 0.161 & 0.323 \\
& & & & & \\
\hline & & & & &
\end{tabular}

\subsection{Business cycle properties: Model versus data}

We now turn to the business cycle properties of our model when the parameters are set at parameters' estimated posterior means.

Table 3 shows standard statistics of the main aggregates and prices of our model. The first column shows the statistics of our data for the interval 1965-2016. The second and third column show the simulated moments by using a first and second order approximation of the model estimated during the same period. ${ }^{33}$ In the Appendix we also provide two robustness checks. First, we repeat the same exercise with shorter series (1965-2006) so as to exclude the Great Recession. Indeed its aftermath featured unconventional monetary policies and non-linear trends in housing markets. Secondly, we repeat the same exercise once more for both time intervals by using alternative house-

\footnotetext{
${ }^{33}$ For the second-order approximation, we use a pruning algorithm (for a discussion about pruning, see Andreasen et al. (1)).
} 
price data (using the FHFA house price index instead of the U.S. Census Bureau house price index on single family homes).

We see that the relative standard deviations of our key variables of interest are very close to those in the data although the model predicts a slightly lower volatility - except for residential investment. The model can also reproduce the fact that the volatility of residential investment is much greater than the one for non-residential investment. Moreover, by including renters, the share of collateral-constrained agents decrease and our model provides a good match of debt volatility (for a discussion, see Guerrieri and Iacoviello (18), who match debt volatility by introducing occasionally binding collateral constraints).

The correlations predicted by the model are in line with data and the literature. Notice that, differently from Iacoviello and Neri (25), our model does a good job in reproducing the positive and strong correlation between house prices and consumption without the need of introducing nominal rigidities. ${ }^{34}$ Having said that, the correlation of residential investment with output and house prices, respectively, are smaller than the one in the data, as we expected. ${ }^{35}$ The model however has hard time in reproducing the correlation between interest rates and house prices. This should not surprise the reader. In fact, we do not model (unconventional) monetary policies and have thus a disadvantage in reproducing the series including the financial crisis. Our robustness exercise in the Appendix shows that the model reproduces much better the correlation between house prices and interest rates if we use shorter series which do not include the Great Recession. Our results are also consistent with Favilukis et al. (14) who underline the role of large risk premia throughout that period.

\footnotetext{
${ }^{34}$ Technology shocks seem to play a significant role into it, see the following discussion on the variance decomposition.

${ }^{35}$ As remarked by Iacoviello and Neri (25), this is related to the lack of nominal rigidities.
} 
Table 3: Baseline model, moments for period 1965-2016.

\begin{tabular}{cc}
\hline Data & \multicolumn{2}{c}{ Baseline model } \\
\cline { 2 - 2 } & \\
\hline
\end{tabular}

$\begin{array}{lll}\text { Std output } \quad 1.69 & 1.04 & 1.05\end{array}$

Standard deviations relative to output:

$\begin{array}{llll}\text { House prices } & 1.57 & 1.37 & 1.55 \\ \text { Rent-price ratio } & 2.05 & 1.63 & 1.78 \\ \text { Consumption } & 0.84 & 0.80 & 0.79 \\ \text { Non-residential investment } & 2.77 & 3.01 & 3.04 \\ \text { Residential investment } & 6.91 & 7.67 & 9.86 \\ \text { Private debt } & 1.88 & 1.49 & 1.79 \\ \text { Interest rate } & 0.21 & 0.38 & 0.38\end{array}$

Cross-correlation between output and

$\begin{array}{llll}\text { Consumption } & 0.93 & 0.81 & 0.79 \\ \text { Residential investment } & 0.70 & 0.43 & 0.39 \\ \text { Non-residential invesment } & 0.70 & 0.70 & 0.70 \\ \text { House prices } & 0.53 & 0.30 & 0.22\end{array}$

Cross-correlation between house prices and

$\begin{array}{lccc}\text { Consumption } & 0.45 & 0.38 & 0.35 \\ \text { Residential investment } & 0.63 & 0.38 & 0.20 \\ \text { Rent-price ratio } & -0.76 & -0.05 & -0.23 \\ \text { Interest rates } & 0.04 & -0.18 & -0.15\end{array}$

Notes: Data include series for the period 1965-2016. "1st order": predictions from model simulated with a first order approximation. "2nd order": predictions from model simulated with a second order approximation with pruning. Results are provided after all shocks. Results come from a simulation of the model of a 30000-periods length. The first 500 periods have been truncated. HP filter, lambda $=1600$. Aggregates are expressed in per capita units.

Table 4 presents a brief inspection of the variance decomposition of our variables of interest. Technological shocks in both sectors are the key drivers of the dynamics of output and consumption. Technological shocks in the housing sector also have a strong impact on the rent-price ratio and residential investment. The ones in the consumption sector have also a large impact on house prices, non-residential investment and on private debt (becauses of prices in the collateral constraint).

Preference shocks for owned housing strongly affect house prices and private debt, as expected, and also rent-price ratios. Discount rate shocks are necessary in our model for the dynamics of the interest rates. 
Finally, while shocks on the marginal efficiency in the consumption sector explain a large share of the dynamics of capital investment and output, the ones in the housing sector explain large shares of the fluctuations of house prices, rent prices, residential investment ${ }^{36}$, private debt and interest rates. Indeed, shocks affecting house prices are transmitted to rent-price ratios and interest rates and/or debt (and viceversa) because of the strong linkage in equation 2.

Table 4: Variance decomposition simulating one shock at a time (in percent)

\begin{tabular}{lccccccc}
\hline & $\epsilon_{A h t}$ & $\epsilon_{A c t}$ & $\epsilon_{j t}$ & $\epsilon_{z t}$ & $\epsilon_{\Upsilon^{c} t}$ & $\epsilon_{\Upsilon h}$ & $\epsilon_{\Omega t}$ \\
\hline GDP & & & & & & & \\
House prices & 25.32 & 56.88 & 0.67 & 0.20 & 11.61 & 2.03 & 2.06 \\
Rent-price ratio & 2.93 & 18.93 & 22.33 & 5.34 & 0.96 & 44.46 & 0.11 \\
Consumption & 12.91 & 0.01 & 42.36 & 4.49 & 0.00 & 34.68 & 5.94 \\
Non-residential investment & 20.54 & 70.99 & 0.08 & 0.04 & 2.98 & 0.27 & 1.91 \\
Residential investment & 32.40 & 0.04 & 0.05 & 0.40 & 54.89 & 3.69 & 0.99 \\
Private debt & 2.13 & 12.52 & 20.07 & 0.47 & 0.01 & 54.69 & 0.06 \\
Interest rate & 2.49 & 4.14 & 5.89 & 72.87 & 0.95 & 56.83 & 3.09 \\
& & & & & & & \\
\end{tabular}

Notes: Results come from a simulation of the model of a 30000-periods length. The first 500 periods have been truncated. Second-order approximation with pruning. HP filter, lambda $=1600$. Aggregates are expressed in per capita units.

\section{Dynamic properties of the model}

To highlight the mechanisms at the roots of our results, we now study the dynamic response of our model to standard macroeconomic shocks, which are key for housing markets. ${ }^{37}$

\subsection{Response to a technological shock in the consumption-good sector}

Following a positive technological shock in the consumption-good sector (an increase $\epsilon_{\text {Act }}$ in equation 16), output and aggregate consumption increase, as expected (see Figure 2). Moreover, the model generates a positive response of capital investment in both sectors (see Figure 3). Absent adjustment costs, there would be a full shift of resources from one sector to the other (see Davis and Van Nieuwerburgh (11)). The presence of adjustment costs for sector-specific capital as well as the fixed

\footnotetext{
${ }^{36}$ This shock helps matching the volatility of residential investment, which we would otherwise have hard time to reproduce in the absence of nominal rigidities. Indeed, if we had to rely on technology shocks only, their larger required size would entail a counter-factual negative correlation between house prices and residential investment.

${ }^{37}$ IRFs refer to a second order approximation of the model with pruning (for a discussion, see Andreasen et al. (1))
} 
Figure 2: Response to a technological shock in the consumption-good sector
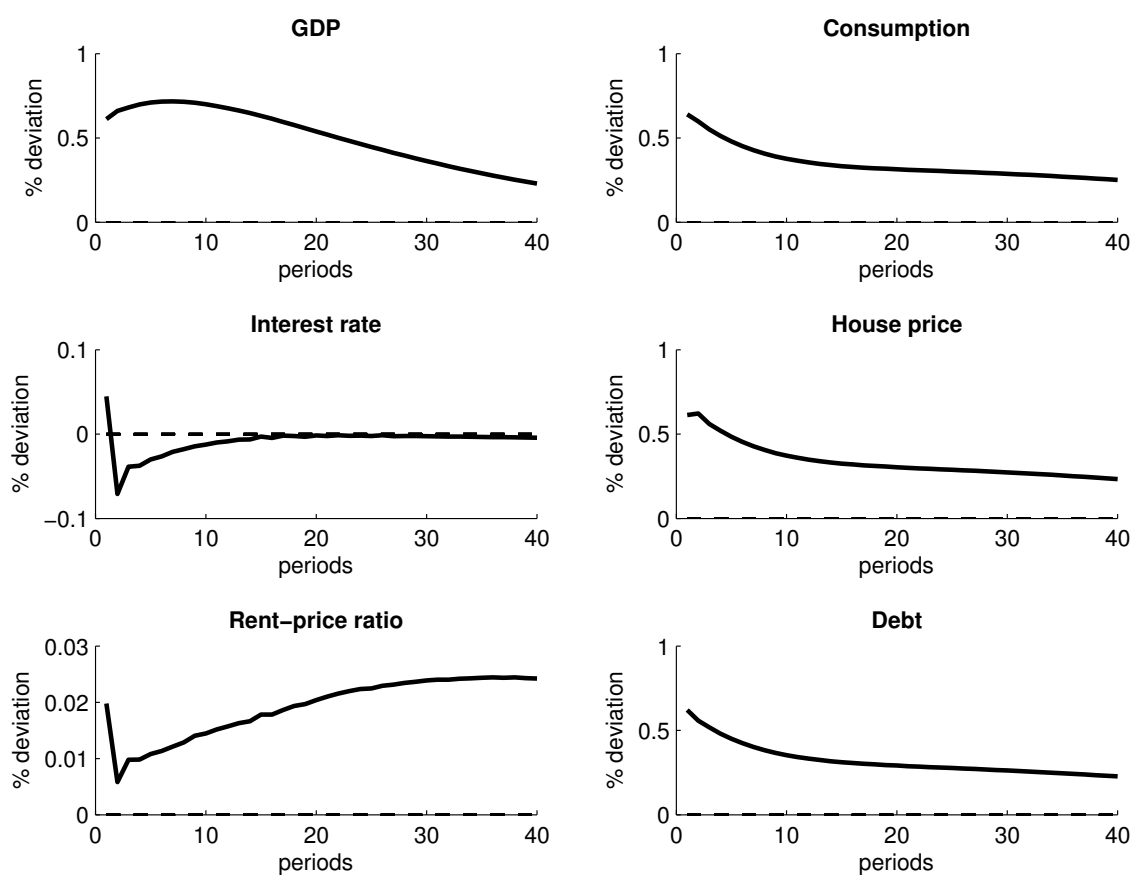

Notes: Simulated impulse response functions after a calibrated positive technological shock in the consumption-good sector. Aggregates are expressed in per capita units. Consistently with national statistics, aggregate consumption also includes housing services (relative prices are kept fixed).

supply of land (which effectively acts as an adjustment cost) prevents this type of effect, which would otherwise generate too much volatility of investment. Adjustment costs also play an important role in the dynamics of the interest rate on loans because capital and financial returns are linked, and the former are affected by the fluctuations of the price of capital. ${ }^{38}$

At the time of the shock, house prices jump high because the productivity in the housing sector falls with respect to the one in the consumption sector (see Figure 2). Because of the strong link in equation 2, the rent-price ratio follows closely the dynamics of the interest rate. ${ }^{39}$

\footnotetext{
${ }^{38}$ As productivity increases in the consumption sector, the marginal return on capital increases as well. The following rise in investment pushes up the relative price of capital, because of adjustment costs. Since capital and financial returns are linked, this initially leads to a rise in the interest rate. Starting from period 3, as investment increases less rapidly, both the size of the adjustment costs and the price of capital decrease. Therefore, although the marginal return on capital remains high because of higher productivity, the decrease in the price of capital dampens its return. That is why, after an initial rise, we observe a fall in the interest rate. Indeed, ruling out arbitrage in equilibrium implies that expected returns on capital and on loans align. In the absence of adjustment costs (and thus changes in the relative price of capital), the interest rate would track the smooth dynamics of the marginal return on capital, which follows in turn the dynamics of the productivity shock.

${ }^{39}$ This is because house prices remain stable between periods 1 and 2 in Figure 2 (i.e., there are no capital gains/losses on housing between periods 1 and 2). Thus, the interest rate and the rent-price ratio initially move together (see equation 2). Starting from period 2, house prices (are expected to) decrease, which results in capital losses and thus a fall of the rent-price ratio with respect to the interest rate.
} 
As house prices increase, the value of the collateral of agents 2 rises, which relaxes their debt limit and enables them to borrow more (Figure 2). Agents of type 2 use these additional funds to increase non-durable consumption and lower their worked hours. This behavior is reinforced by an income effect associated to the increase in wages (Figure 3), which further dampens worked hours. Higher wages also explain why agents of type 3 can afford both more consumption goods and housing services (Figure 3) even if the latter are more expensive.

Figure 3: Response to a technological shock in the consumption-good sector
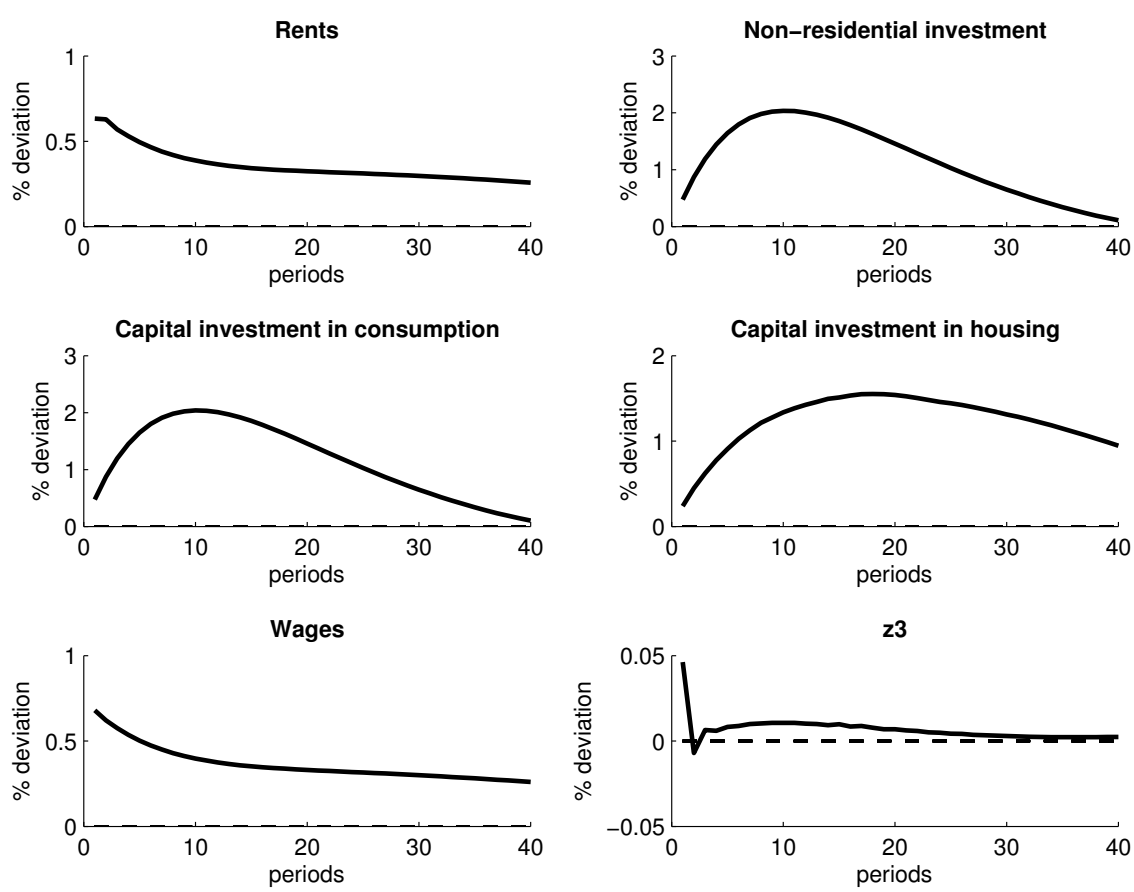

Notes: Simulated impulse response functions after a calibrated positive technological shock in the consumption-good sector. Non-residential investment is expressed in per capita units and is the sum of capital investment in the consumption-good sector and capital investment in the housing sector. z3 refers to rented units by agent 3 .

\subsection{Demand shocks for owned housing units}

We now shift our attention to the effects of preference shocks for owned housing (an increase in $\epsilon_{j t}$ in equation 7). These shocks are very common in the housing literature starting from Iacoviello (24) because of their ability to reproduce house-prices dynamics consistent with data. The increase in $j_{t}$ triggers a jump in housing demand of both agents 1 and 2. As expected, the demand shock pushes 
Figure 4: Response to a preference shock for owned housing
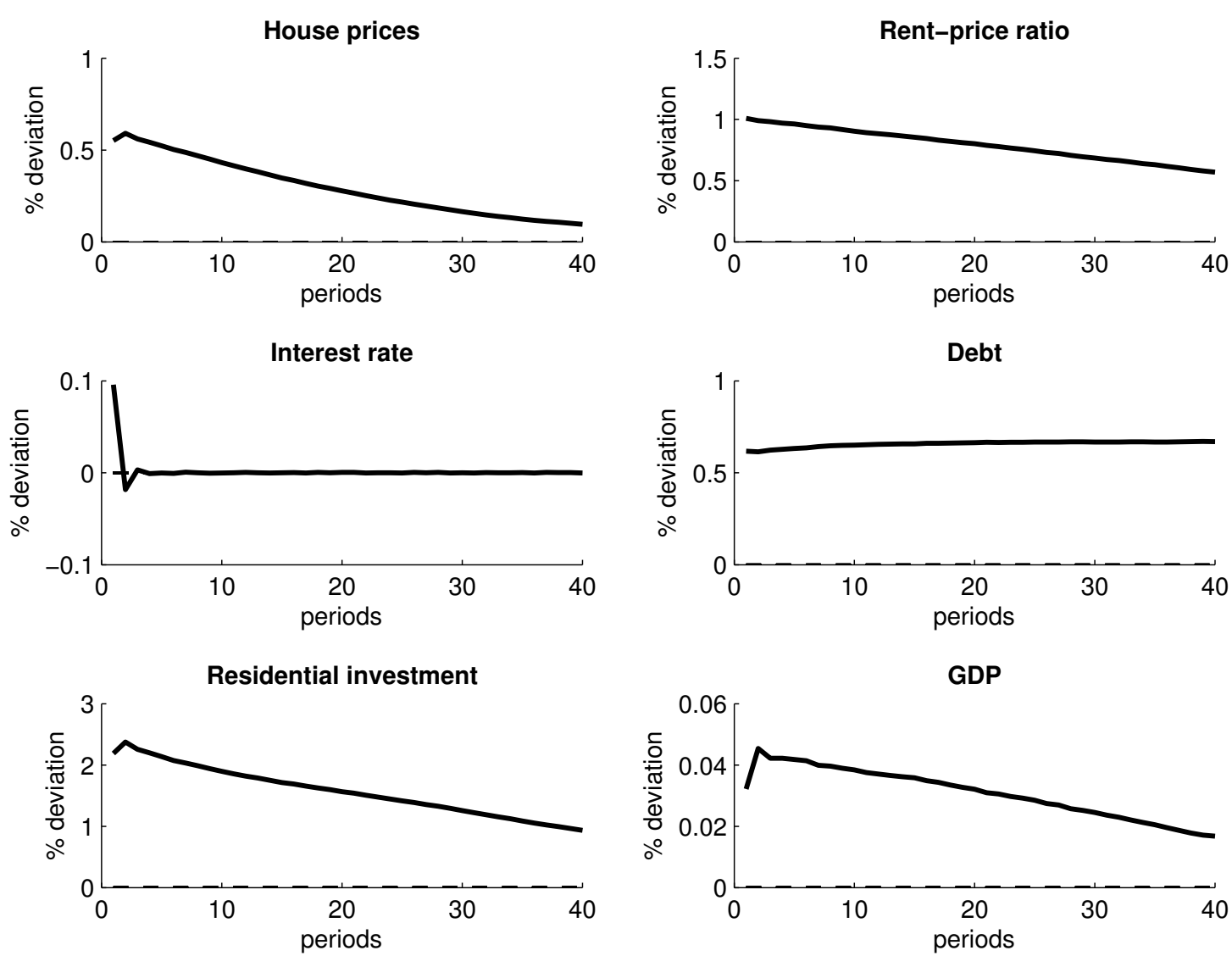

Notes: Simulated impulse response functions after a calibrated positive preference shock for owned housing. Residential investment refers to output in the housing sector while investment refers to capital accumulation in both sectors. Aggregates are expressed in per capita units. 
up house prices (see Figure 4). ${ }^{40}$ The increase in demand also leads firms to produce more housing and allow our model to reproduce the positive correlation between house prices and residential investment observed in the data (see Iacoviello and Neri (25)). Collateral effects associated to the behaviors of agents of type 2 amplify the upward pressure on both house prices and residential investment, and thus, on total output. There is also an increase in the interest rate, even if shortlived. This is due to the jump in house prices, that push up the collateral value and allow the impatient agent to borrow more. Once house prices start declining, the value of the collateral decreases together with agents' 2 demand for credit and the interest rate on loans. Aggregate consumption follows the same trend.

Since the impact of the shock on the interest rates is short-lived and interest rates come back quickly towards the steady state, the dynamics of the rent-price ratio essentially track the one of house prices (see equation (2)). Therefore, in response to the demand shock for housig, house prices and rent-price ratios (together with nominal rents) increase.

\section{$6 \quad$ Housing markets during Covid times}

While the US economy was dramatically affected by the Covid-19 pandemic, its housing market has experienced a boom. In particular, the following stylized facts have characterized the US housing market after the outbreak of Covid (see Figure 5):

1. House prices have risen substantially. This is the case for urban, suburban and rural areas (see Zhao (43)). ${ }^{41}$

2. Rent-price ratios have decreased significantly. This trend is also confirmed at a disaggregated level by accounting for housing quality (see the report of Joint Center for Housing Studies of Harvard University, JCHSHU (20)). ${ }^{42}$

\footnotetext{
${ }^{40}$ Notice that the effect is magnified here by the fact that land is in fixed supply.

${ }^{41}$ See also housing price increases for the vast majority of US cities included in the S\&P/Case-Shiller 20-City Composite Home Price Index.

${ }^{42}$ Rent-price ratios have also decreased at an urban, suburban or rural level. This is consistent with past evidence on rent-price ratios following outbreaks of the plague in 17th-century Amsterdam and cholera in 19th-century Paris (see Francke and Korevaar(16)). Rents have generally decreased too, with some exceptions (see Gupta et al. (19)),
} 
3. In response to the severity of the effects of the Covid pandemic, the Fed cut the reference interest rate to $0-0.25 \%$ in March 2020 and in June 2020 engaged to keep it low through 2022. This has been transmitted to record-low mortgage rates (see JCHSHU (20)).

4. Despite the fact that lending standards have tightened, mortgage debt has continued to rise. Moreover, the delinquency rate on mortgages has not significantly increased (JCHSHU (20)).

5. Residential investment dropped in the second quarter of 2020 but went back to its pre-crisis trend in the third quarter. Notice also that the pre-crisis period was featured by several quarters of particularly strong growth in residential investment.

While the driving forces behind these facts are still debated, our simple model can serve as a useful tool to provide a better understanding of the underlying economic mechanisms. Indeed, its simple structure allows both to reproduce housing markets dynamics and to track the transmission channels.

Supply factors are in the list of usual suspects because the Covid crisis strongly disrupted supply in many sectors. However, several considerations do likely dismiss supply shortages as main drivers of recent trends. First, the fall in housing supply lasted very short and was preceded by a steady growth in residential investment (see Figure 5). Second, housing sales have increased above the trend starting from summer 2020 (JCHSHU (20)). Finally, supply shortages can in principle explain the increase in house prices but they hardly rationalize the contemporaneous decrease of the rent-price ratio and interest rates.

Demand factors seem more probable drivers of the observed dynamics. The restrictions in response to the pandemic have indeed imposed strong limits to consumption possibilities. They have particularly limited non-durable consumption while being less restrictive towards durable consumption. Not surprisingly, personal savings have spiked. ${ }^{43}$ The pandemic has also imposed distance working so that have stagnated on average. Having said that, since the rise in house prices has been more significant, the decrease of rent-price ratios is confirmed.

${ }^{43}$ In March 2020 personal saving jumped to levels that were more than six times greater than pre-crisis ones. In January 2021 personal saving was still 4 times greater pre-crisis saving. See https://fred.stlouisfed.org/series/ PMSAVE. 
Figure 5: Housing trends during covid times

(a) House prices

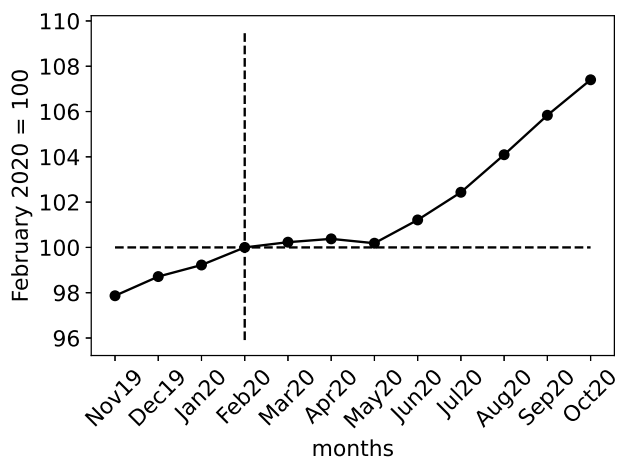

(c) Interest rate

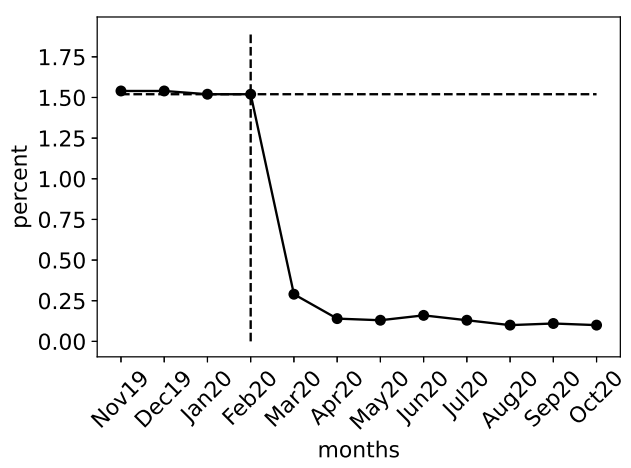

(b) Rent-price ratio

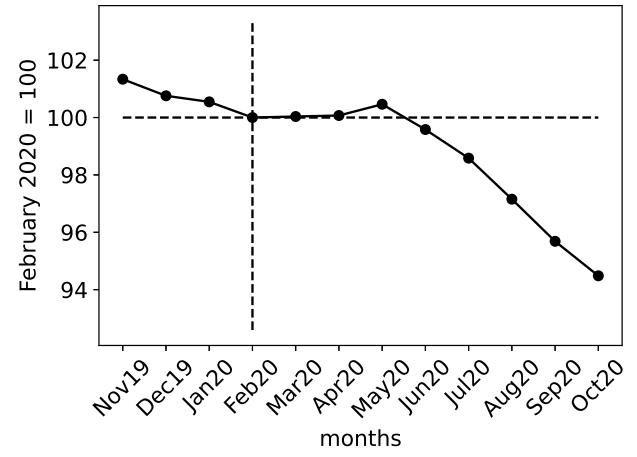

(d) Household debt

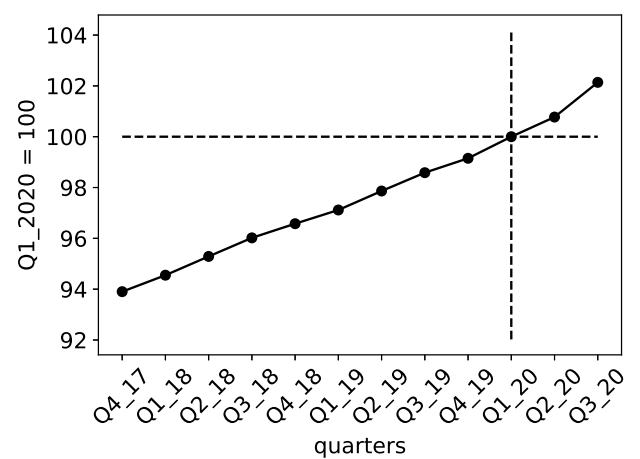

(e) Residential investment

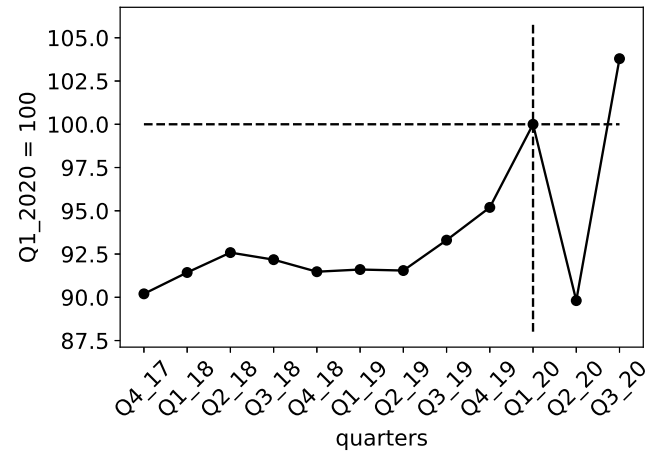

Sources: See Appendix C.3. 
Figure 6: Response to a shock to intertemporal preferences
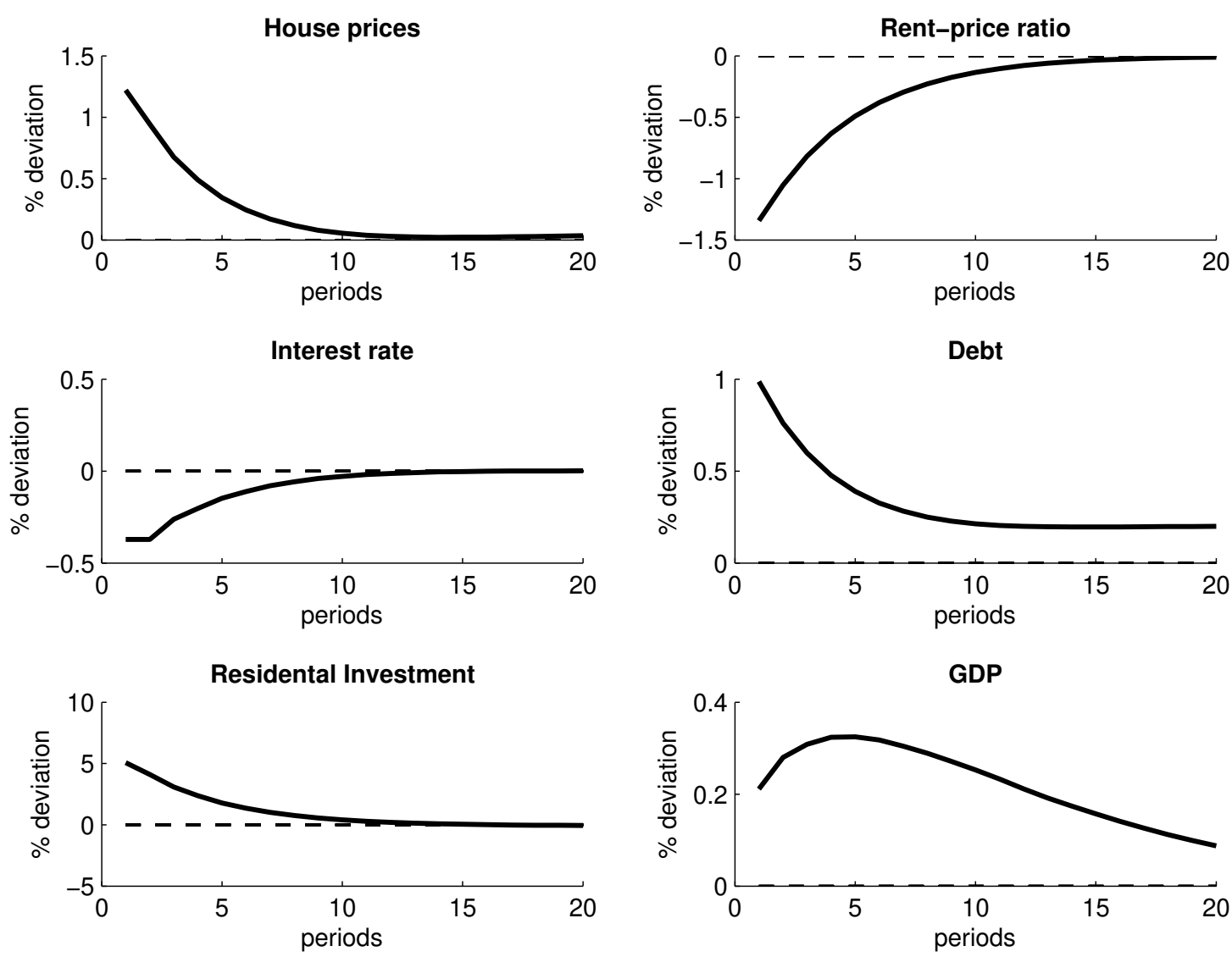

Notes: Simulated impulse response functions after a calibrated shock to intertemporal preferences. Debt is expressed in per capita units.

and as many people were forced to spend more time at home, some started looking for bigger places to live. ${ }^{44}$ These changes in behaviors share the common root of being policy-induced changes in preferences. Preference shocks have been extensively used in the housing macroeconomic literature and are commonly proxied by an intratemporal increase in the demand of housing over the one for non-durables (a shock on $j_{t}$ in our model, see equation (7)). In section 5.2, we have studied the qualitative effects of a standard intratemporal demand shock for housing à la Iacoviello (24). Such a shock is in line with an increase in house prices, debt and residential investment. However, while triggering a substitution effect in favor of housing (especially for the agents who are not subject to the collateral constraint), it fails to explain the drop in the rent-price ratio and interest rates. Indeed, an increase in the preference for housing over consumption drives up the relative price of

\footnotetext{
${ }^{44}$ In some cases, many households decided to flee the cities. The above focus on rural vs urban house prices and rent-price ratios suggests that the fleeing-to-rural areas phenomenon is not the dominating force.
} 
housing consumption (i.e. rents) and pushes up the demand for borrowing, therefore driving up the interest rate. Alternatively, intertemporal changes in behaviors are proxied by intertemporal preferences shocks à la Guerrieri and Iacoviello (18). These shocks introduce a tilt in agents' preferences for current vs future consumption (i.e., saving) and have the advantage of being consistent with the recent surge in personal saving. In our model they correspond to equation (4) and drive up the demand for tomorrow's consumption over today's one.

In what follows we argue that while the restriction-induced change in intratemporal preferences surely had some impact on the observed housing market dynamics, the tilt in intertemporal preferences induced by the restrictions have likely played a greater role. Indeed, as we show in the next section, a shock to intertemporal preferences is globally in line with all the patterns in figure 5 .

\subsection{Response to a pandemic-induced tilt in intertemporal preferences}

We now calibrate the intertemporal preference shock of equation (4) so as to track the recent evidence. Starting in Spring 2020, the Fed injected liquidity so as to cut interest rates. As a result, the (annualized) interest rate on 3-month T-bills went from about 1.50\% in February 2020 to close to 0\% in April 2020 ( see Figure 5). The announcement of Jerome Powell on June 10th 2020 for the Fed to keep the funds rate between $0 \%$ and $0.25 \%$ throughout 2022 contributed to drive down longterm interest rates as well (e.g the interest rate on 10-year treasuries went down by 0.84 percentage points during the same period).

We therefore pin down the persistence of the shock during the pandemic so that it mostly dies out after 3 years, which is globally in line with Powell's commitment. More precisely, we set $\rho_{\beta}$ so that after 12 quarters the shock is only $5 \%$ of its initial value. As a result $\rho_{\beta}=0.05^{1 / 12} \simeq 0.78$. We then calibrate the standard deviation of $\epsilon_{\beta t}$ so that the initial decline in the quarterly interest rate is about 0.375 percentage points, consistently with the data. ${ }^{45}$

\footnotetext{
${ }^{45}$ The 5-year forward inflation expectation rate went from $1.65 \%$ in February 2020 to $1.30 \%$ in March 2020 (see https://fred.stlouisfed.org/series/T5YIFR). Thus, expected real interest rates went initially down by less than nominal ones. However, inflation expectations surpassed their February-2020 level in August 2020, thus expected real interest rate then went down more that nominal ones. This suggest that, over the whole period, the decline in the nominal and real interest rates was very similar. This is particularly the case in light of generalized very low inflation levels. For simplicity, the decline in the real interest rate (of our model) is set in our exercise so as to be the
} 
Figure 6 shows the response of the economy to the calibrated intertemporal preference shock, which is in line with the stylized facts highlighted in Figure 5. The shock directly affects intertemporal decisions and thus hits the Euler equation of agents of type 1 (i.e., the dominant consumers). They choose to postpone current consumption of non-durable goods and housing services, while they supply more savings, labor and invest in housing (to rent). This is consistent with the strong jump in personal savings starting from March 2020. As agents of type 1 pin down the interest rate, this change in intertemporal behavior pushes the interest rate down. This also mimics the Fed policy, that has accommodated the surge of saving with large liquidity injections to stimulate the economy.

In equilibrium, these additional savings are associated with an increase of loans supplied to agents of type 2 and with an increase in capital stocks of both sectors. As their intertemporal preferences are also modified, agents of type 2 do also reduce their current consumption and accumulate more housing (and thus debt). Contrarily to the two previous ones, agents of type 3 solve a static problem and are not directly affected by the shock, although their behaviors are impacted by the change in equilibrium prices.

The shock we consider in this section thus tracks both the large rise in aggregate saving and the decrease in the interest rate. The implied increase in the demand for housing, from both agents 1 and 2, pushes house prices up. Importantly, this does not translate into an increase in rents. In contrast, the rent-price ratio decreases. This is due to the fact that agents of type 1 are supplying more housing on the rental market. It explains why agents of type 3 are consuming more housing services and less non-durables. ${ }^{46}$ Notice finally that the effect of the pandemic-induced shock is amplified by housing markets, who drive up both residential investment (i.e., housing output) and aggregate GDP.

The relationship between interest rates, housing prices and the rent-to-price ratio is clearly characterized by equation (2). It shows that the interest rate is strongly linked with the product of same as the decline of the nominal interest rate observed in the data. More in particular, we match the observed fall in nominal interest rate with the average of the fall of real rates in our model during the first two periods.

${ }^{46}$ Notice that labor supply of agents of type 1 increase and wages are pushed down so that the revenues of agent 3 decrease. 
housing prices and the rent-price ratio. Following a shock that reduces the interest rate, a rise in housing price is associated with a decline in the rent-price ratio (see the results of the SVAR of Dias and Duarte (12)). The return on housing investments is in this case positively correlated with the interest rate.

\subsection{Housing-induced welfare effects}

The exercise in the previous section has highlighted that the policy-induced change in intertemporal preferences has had an expansionary impact on the housing market. We now shift our attention to its heterogeneous welfare implications, depending on agents status on the housing market. ${ }^{47}$

Figure 7: Welfare effect of the intertemporal preferences shock

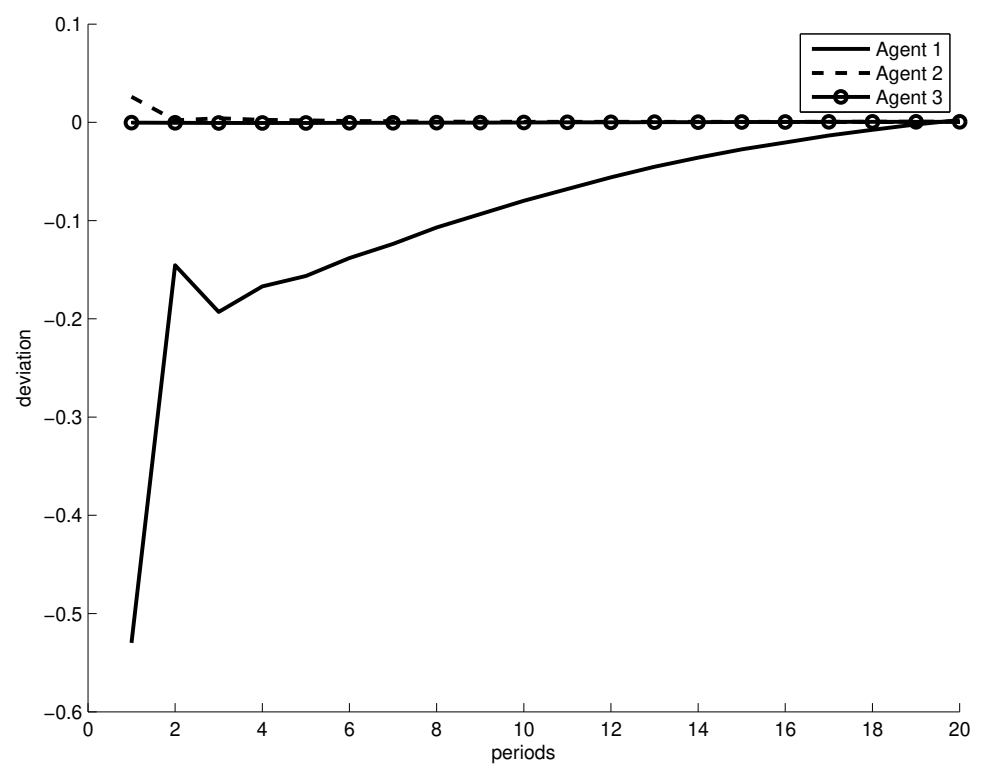

Notes: Simulated impulse response functions after a calibrated intertemporal-preferences shock. IRFs represent percent deviations from steady state of instantaneous utilities of agents of type 1, 2 and 3 , respectively.

Figure 7 plots the response of agents' welfare in response to the shock. Welfare is simply defined here as agent's instantaneous utility. Notice in particular that the shock has a large negative impact on the welfare of landlords. This is because of a negative direct effect on non-durable consumption

\footnotetext{
${ }^{47}$ A full study of Covid's welfare impact on different types of households is beyond scope of this work because it would require to analyze the heterogeneous effect of the pandemic on the job market, as documented in many recent empirical works.
} 
and labor supply, that is associated to the tilt in preferences. ${ }^{48}$ But there is also a significant indirect effect of the shock, that is transmitted to their welfare via their revenues. Indeed, because of the fall in interest rates and the associated one in rents, landlords experience a significant decrease in financial revenues (see Figure 8). In contrast, the welfare of renters is barely affected. Indeed, the fall in rent-price ratios partly compensates the decrease in wages and thus, the fall in renters' incomes. Finally, the fall in interest rates drives down credit costs, benefiting borrowers.

Contrarily to the common view, our analysis suggests thus that recent policies pushing down interest rates have particularly weighted on landlords although lower interest rates have contributed to drive up the value of housing (and the wealth of homeowners). Our framework show how low rates can be beneficial to lower income households, who rent and borrow. ${ }^{49}$

Figure 8: Asset income and interests on debt
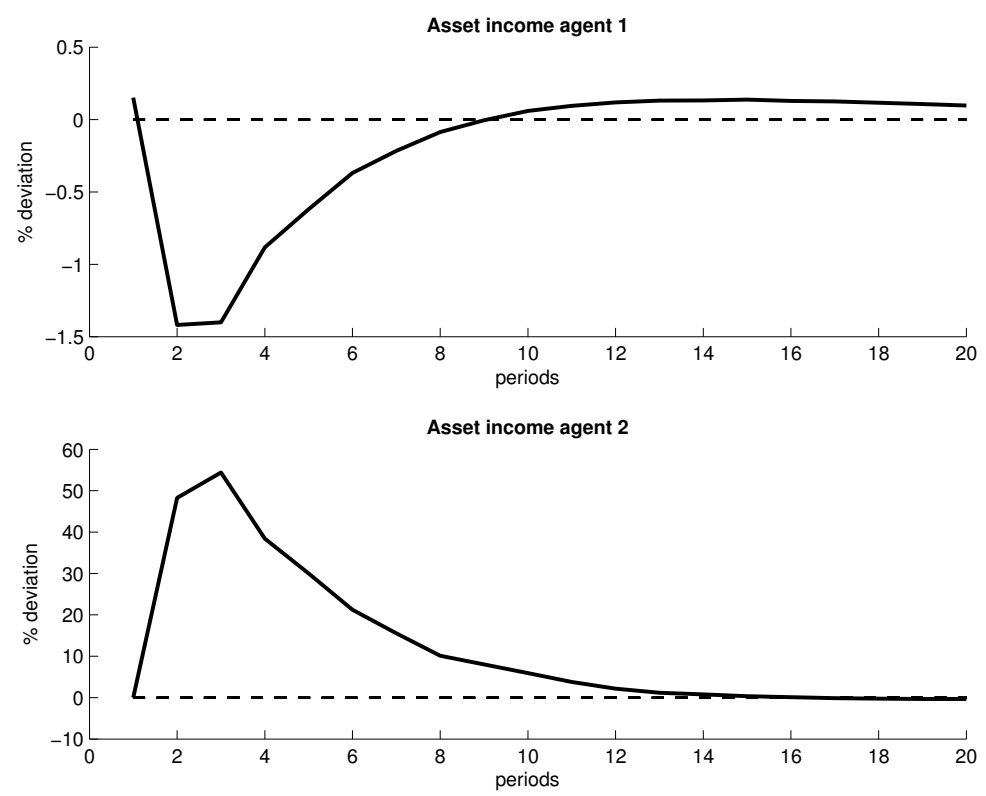

Notes: Simulated impulse response functions after a calibrated intertemporal-preferences shock. IRFs represent percent deviations from steady state of asset income for agent 1 (first panel) and for agent 2 (second panel). Agent's 1 assets income is defined as: $p_{t}\left[l_{t}-\delta_{x}\right] h_{1 t} x_{1 t-1}+r_{t}^{c} k_{t-1}^{c}+r_{t}^{h} k_{t-1}^{h}+$ $p_{t}^{q} l_{t}^{q} q_{t-1}-\left(R_{t-1}^{d}-1\right) d_{1 t-1}$, consistently with Proposition 1 and 2. Agent's 2 assets income is defined as: $-\left(R_{t-1}^{d}-1\right) d_{2 t-1}$.

There is thus an important channel linking agents' welfare with the role they play on housing

\footnotetext{
${ }^{48}$ The shock triggers an increase of landlords' labor supply and a decrease in consumption so that their utility is dampened.

${ }^{49}$ Because of the same mechanisms, an intratemporal shock for housing drives up both rent and borrowing costs and hurts both renters and borrowers.
} 
markets because of heterogeneous financial revenues. In our model, this is due to changes in rents and interest rates. As remarked by Pereira Da Silva ${ }^{50}$ because "..households at the bottom of the distribution are renters, the middle class owns mainly real estate and bank deposits, and those at the top own more sophisticated (and higher-yielding) financial assets..' monetary expansion seems to increase wealth inequality. There is a renewed interest in the effects of low interest rates on inequality. ${ }^{51}$ The debate is far from being closed and recent evidence points instead in favor of a decrease of inequality when the monetary policy is expansionary. ${ }^{52}$ While the evaluation of the distributional effects of current policies is beyond the scope of our work, our results contribute to the debate by pointing out the importance of the social stratification induced by the housing market. Our parsimonious framework helps clarifying the heterogeneous impacts of low interest rates policies on households according to the role they play on housing markets.

\section{Conclusion}

This paper proposes a model that explicitly distinguishes real estate and rental markets. In this framework, the behavior of agents that are heterogeneous with respect to their housing status allows to determine endogenously both housing and rental prices. In equilibrium, the rent-to-price ratio is tightly linked to interest rates through an arbitrage condition, which is at the roots of the main economic mechanisms at play. The model is estimated with standard Bayesian methods to match the US data of the last decades and is an useful framework to study the dynamics on housing

\footnotetext{
50"Monetary policy, technology and inequality", Peterson Institute for International Economics roundtable: "Central banking and inequality: Covid-19 and beyond", 11 December 2020, Centre for Economic Policy Research International Monetary Fund.

${ }^{51}$ See M. Draghi's talk on "Stability, equity and monetary policy" (German Institute for Economic Research, Berlin, 25 October 2016) and J. Yellen's one on "Perspectives on Inequality and Opportunity from the Survey of Consumer Finances" (Conference on Economic Opportunity and Inequality Federal Reserve Bank of Boston, October the 17th 2014). See also (? ).

${ }^{52}$ Coibion et al. (8) study the effect of monetary policy shocks on consumption and income inequality. Even if their focus in not explicitly on wealth by studying consumption they document some of the different channels through which monetary policy shocks affect inequality. Based on household-level micro data, they provide evidence in support of distributional effects of monetary policies. They also find that contractionary shocks raise inequality while expansion mitigates it. More recently, Hohenberger et al. (23) compare the distributional effects of Taylor rules and quantitative easing within an estimated open-economy DSGE model. Their model considers both hand-to-mouth and dynamic optimizing agents with access to bonds and equity and account thus explicitly for some forms of financial wealth. They show how expansionary monetary policies, both in the form of Taylor rules and quantitative easing, tend to mitigate income and wealth inequality between the two population groups.
} 
markets. It allows us to explain and reproduce the main stylized facts featuring current trends. The model also allows for welfare comparisons. It suggests that the housing-rich agents, namely the landlords, are those who are suffering the most of the consequences of Covid-induced policy shocks. This research can be extended in various directions. Most notably, the market for business real properties and its relation with the housing market would be an interesting research avenue as remote working might increase as a consequence of the pandemics. Moreover, our model ignores the spatial dimention of housing choices that are also likely to be modified in the coming years. 


\section{References}

[1] Andreasen M. M., Fernandez-Villaverde J., Rubio-Ramirez J. F. (2018), The Pruned StateSpace System for Non-Linear DSGE Models: Theory and Empirical Applications, The Review of Economic Studies, 85(1), 1-43.

[2] Andrews, D. and A. Caldera Sanchez (2011), Drivers of Homeownership Rates in Selected OECD Countries, OECD Economics Department Working Papers 849.

[3] Becker, R. and Foias, C. (1987), A characterization of Ramsey equilibrium. Journal of Economic Theory 41, 173-184.

[4] Calza, A., Monacelli, T. and Stracca, L. (2013), Journal of the European Economic Association 11 (S1), 101-122.

[5] Christiano, L., Motto R., Rostagno, M. (2014), Risk shocks. American Economic Review 104(1), $27-65$.

[6] Christiano, L. Trabandt, M., Walentin, K. (2011), Introducing financial frictions and unemployment into a small open economy model. Journal of Economic Dynamics and Control 35(12) 1999-2041.

[7] Christophers, B. (2019), A tale of two inequalities: Housing-wealth inequality and tenure inequality, Environnement and Planning: Economy and Space, https://doi.org/10.1177/ $0308518 X 19876946$.

[8] Coibion, O., Gorodnichenko Y., Kueng L. and Silvia J. (2017), Innocent Bystanders? Monetary policy and inequality, Journal of Monetary Economics 88, 70-89.

[9] D'Albis, H. and Iliopulos, E. (2013), Collateral constraints and rental markets. Economics Letters 121(3), 436-439.

[10] Davis, M. A., Heathcote, J. (2005), Housing and the business cycle, International Economic Review 46(3), 751-784. 
[11] Davis, M. A. and Van Nieuwerburgh, S. (2015), Housing, finance, and the macroeconomy. In: G. Duranton, J. V. Henderson and W. C. Strange (eds.), Handbook of Regional and Urban Economics, edition 1, volume 5, chapter 12, pages 753-811, Elsevier.

[12] Dias A. D. and J.B. Duarte (2019), Monetary policy, housing rents, and inflation dynamics, Journal of Applied Econometrics, 34(5), 673-687.

[13] Favara, G. and Imbs, J. (2015), Credit Supply and the Price of Housing, American Economic Review, 105(3), p. 958-92.

[14] Favilukis, J., Ludvigson S. C., Van Nieuwerburgh, S. (2016), The macroeconomic effects of housing wealth, housing finance, and limited risk sharing in general equilibrium, Journal of Political Economy 125(1), 140-223.

[15] Ferrero, A. (2015), House price booms, current account deficits, and low interest rates. Journal of Money, Credit and Banking 47, 261-293.

[16] Francke, M. and Korevaar M. (2021), Housing Markets in a Pandemic: Evidence from Historical Outbreaks. Journal of Urban Economics 123.

[17] Garriga, C., Manuelli, R. and Peralta-Alva A. (2019), A Macroeconomic Model of Price Swings in the Housing Market, American Economic Review 2019, 109(6), 2036-2072.

[18] Guerrieri, L. and Iacoviello, M. (2017). Collateral constraints and macroeconomic asymmetries. Journal of Monetary Economics 90(C), 28-49.

[19] Gupta, A., Mittal V., Peeters J. and Van Nieuwerburgh, S. (2021). Flattening the Curve: Pandemic-Induced Revaluation of Urban Real Estate. Mimeo

[20] Joint Center for Housing Studies of Harvard University (2020), The State of the Nation's Housing 2020.

[21] Henderson J., V. and Ioannides Y., M. (1983), A model of housing tenure choice. American Economic Review 73(1), 98-113. 
[22] Hendricks, L. (2007). How important is discount rate heterogeneity for wealth inequality? Journal of Economic Dynamics and Control 31(9), 3042-3068.

[23] Hohberger, S., R. Priftis and L. Vogel (2020), The distributional effects of conventional monetary policy and quantitative easing: Evidence from an estimated DSGE model, Journal of Banking and Finance 113

[24] Iacoviello, M. (2005), House prices, borrowing constraints, and monetary policy in the business cycle. American Economic Review 95(3), 739-764.

[25] Iacoviello, M. and Neri, S. (2010), Housing market spillovers: Evidence from an estimated DSGE model, American Economic Review: Macroeconomics 2, 125-164.

[26] Iacoviello, M. and Pavan, M. (2013), Housing and debt over the life cycle and over the business cycle. Journal of Monetary Economics 60, 221-238.

[27] Justiniano, A., Primiceri G., Tambalotti, A. (2011), Investment shocks and the relative price of investment. Review of Economic Dynamics 14(1), 101-121.

[28] Justiniano, A., Primiceri G., Tambalotti, A. (2018), Household leveraging and deleveraging. Review of Economic Dynamics 18(1), 3-20.

[29] Justiniano, A., Primiceri G., Tambalotti, A. (2019), Credit supply and the housing boom, Journal of Political Economy 127(3), 1317-1350.

[30] Kaplan, G., Mitman, K., Violante, G. L., (2020). The housing boom and bust: Model meets evidence. Journal of Political Economy, 128(9)

[31] Kiyotaki, N., Michaelides A., Nikolov, K. (2011), Winners and losers in housing markets. Journal of Money, Credit and Banking 43(2-3), 255-296.

[32] Kiyotaki, N. and Moore, J. (1997), Credit cycles. Journal of Political Economy 105, 211-248.

[33] Liu, Z., Wang. P., Zha, T. (2013), Land-price dynamics and macroeconomic fluctuations. Econometrica 81(3), 1147-1184. 
[34] Meyer-Gohde, A. (2010), Matlab code for one-sided HP-filters, QM\&RBC Codes 181, Quantitative Macroeconomics \& Real Business Cycles

[35] Nakajima, M. and Telyukova, I. A., (2020), Home Equity in Retirement, International Economic Review 61(2), 573-616.

[36] Ngai, L. R. and Tenreyro S. (2014), Hot and Cold Seasons in the Housing Market, American Economic Review, 104(12), 3991-4026.

[37] Pfeifer, J., (2020), A Guide to Specifying Observation Equations for the Estimation of DSGE Models

[38] Silos, P. (2007), Housing, portfolio choice and the macroeconomy. Journal of Economic Dynamics and Control 31(8), 2774-2801.

[39] Sommer, K., Sullivan P., Verbrugge, R. (2013), The equilibrium effect of fundamentals on house prices and rents, Journal of Monetary Economics 60, 854-870.

[40] Sommer, K. and Sullivan, P.(2018), Implications of the U.S. Tax Policy for House Prices and Rents, American Economic Review 108(2), 241-274.

[41] Stock, J.H. and Watson, M.W. (1999), Forecasting inflation, Journal of Monetary Economics, vol. 44(2), 293-335.

[42] Wong, G. (2008), Has SARS infected the property market? Evidence from Hong Kong, Journal of Urban Economics 63, 74-95.

[43] Zhao, Y. (2020), US Housing Market during COVID-19: Aggregate and Distributional Evidence, IMF Working Paper, 20/212. 


\section{Appendix}

\section{A Proofs for model of section 2}

Proof of Proposition 1. The first order conditions of problem (1) write:

$$
\begin{aligned}
& 1-\frac{\mathbb{E}_{t} \beta_{i t+1} R_{t} u_{c_{i t+1}}^{\prime}}{u_{c_{i t}}^{\prime}}-\mu_{i t}=0 \\
& -p_{t}+\frac{\mathbb{E}_{t} \beta_{i t+1} p_{t+1}\left[\left(1-\delta_{x}\right)+l_{t+1}\left(1-h_{i t+1}\right)\right] u_{c_{i t+1}}^{\prime}}{u_{c_{i t}}^{\prime}}+\frac{\mathbb{E}_{t} \beta_{i t+1} h_{i t+1} u_{h s_{i t+1}}^{\prime}}{u_{c_{i t}}^{\prime}} \\
& +\mu_{i t} m\left(1-\delta_{x}\right) \mathbb{E}_{t} p_{t+1}+\pi_{i t}^{x}=0 \\
& -p_{t} l_{t} x_{i t-1}+x_{i t-1} \frac{u_{h s_{i t}}^{\prime}}{u_{c_{i t}}^{\prime}}+\pi_{i t}^{h}-\pi_{i t}^{1-h}=0, \\
& -p_{t} l_{t}+\phi \frac{u_{h s_{i t}}^{\prime}}{u_{c_{i t}}^{\prime}}+\pi_{i t}^{z}=0
\end{aligned}
$$

where marginal utilites are denoted $u_{c_{i t}}^{\prime}$ and $u_{h s_{i t}}^{\prime}$, and where $\mu_{i t}, \pi_{i t}^{x}, \pi_{i t}^{z}, \pi_{i t}^{h}$ and $\pi_{i t}^{1-h}$ are the multipliers (divided by $u_{c_{i t}}^{\prime}$ ) associated to non negativity constraints. The complementary slackness conditions are:

$$
\mu_{i t}\left[m\left(1-\delta_{x}\right) x_{i t} \mathbb{E}_{t} p_{t+1}-d_{i t}\right]=\pi_{i t}^{x} x_{i t}=\pi_{i t}^{z} z_{i t}=\pi_{i t}^{h} h_{i t}=\pi_{i t}^{1-h}\left(1-h_{i t}\right)=0 .
$$

Let us first ignore $\mu_{i t}$ and list the possible cases according to the remaining multipliers.

Case 1. $\pi_{i t}^{x}>0$ (and thus $x_{i t}=0$ ); in that case, the assumption on marginal utilities implies $z_{i t}>0$ (and thus $\pi_{i t}^{z}=0$ ). Note that the study of $\pi_{i t}^{h}$ and $\pi_{i t}^{1-h}$ is useless.

Case 2. $x_{i t}>0$ (and thus $\pi_{i t}^{x}=0$ ); we note that having simultaneously $\pi_{i t}^{h}>0$ and $\pi_{i t}^{1-h}>0$ is not possible. We therefore have five sub cases: $i) \pi_{i t}^{h}>0$ (and $h_{i t}=0$ ); the assumption on marginal utilities implies $z_{i t}>0$ (and thus $\pi_{i t}^{z}=0$ ). ii) $\pi_{i t}^{1-h}>0$ (and $h_{i t}=1$ ) and $z_{i t}>0$ (and thus $\pi_{i t}^{z}=0$ ). $\left.i i i\right) \pi_{i t}^{1-h}>0\left(\right.$ and $\left.h_{i t}=1\right)$ and $z_{i t}=0$ (and thus $\left.\pi_{i t}^{z} \geq 0\right)$. iv) $\pi_{i t}^{h}=\pi_{i t}^{1-h}=0$ (and $\left.h_{i t} \in(0,1)\right)$ and $z_{i t}>0$ (and thus $\left.\left.\pi_{i t}^{z}=0\right) . v\right) \pi_{i t}^{h}=\pi_{i t}^{1-h}=0$ (and $\left.h_{i t} \in(0,1)\right)$ and $z_{i t}=0$ (and thus $\left.\pi_{i t}^{z} \geq 0\right)$. 
Rearranging (A.4) and (A.3) by eliminating $p_{t} l_{t}$, we obtain:

$$
x_{i t-1}\left((1-\phi) \frac{u_{h s_{i t}}^{\prime}}{u_{c_{i t}}^{\prime}}-\pi_{i t}^{z}\right)+\pi_{i t}^{h}-\pi_{i t}^{1-h}=0
$$

If $\pi_{i t}^{h}>0$, then $\pi_{i t}^{1-h}=0$ and thus, using (A.6), we conclude that $\pi_{i t}^{z}>0$; thus, Case $2 i$ must be eliminated. If $\pi_{i t}^{h}=\pi_{i t}^{1-h}=0$, we conclude using (A.6) that $\pi_{i t}^{z}>0$; thus, Case 2iv must be eliminated.

Proof of Proposition 2. At the deterministic steady state, the first order conditions of problem (1) write:

$$
\begin{aligned}
& 1-\beta_{i} R-\mu_{i}=0 \\
& -p+\beta_{i} p\left[\left(1-\delta_{x}\right)+l\left(1-h_{i}\right)\right]+\beta_{i} h_{i} \frac{u_{h s_{i}}^{\prime}}{u_{c_{i}}^{\prime}}+\mu_{i} m\left(1-\delta_{x}\right) p+\pi_{i}^{x}=0 \\
& -p l x_{i}+x_{i} \frac{u_{h s_{i}}^{\prime}}{u_{c_{i}}^{\prime}}+\pi_{i}^{h}-\pi_{i}^{1-h}=0 \\
& -p l+\phi \frac{u_{h s_{i}}^{\prime}}{u_{c_{i}}^{\prime}}+\pi_{i}^{z}=0
\end{aligned}
$$

The proof proceed by proving a sequence of claims.

Claim 1. The dominant consumer satisfies $\mu_{1}=0$ while all other agents satisfy $\mu_{i}>0$.

The proof is standard. It relies on the fact that if some agents lend to others, their $\mu_{i}$ should be zero. Then, the only possible configuration given by (A.7) is $\mu_{1}=0, \beta_{1}=R$ and $\mu_{i}=1-\beta_{i} / \beta_{1}>0$ for all $i=2,3, \ldots N$. Thus, from (A.5), we conclude that $d_{i}=m\left(1-\delta_{x}\right) x_{i} p$ for all $i=2,3, \ldots N$, while $d_{1}<0$.

Claim 2. There is only one landlord, who is the dominant consumer.

To show this let us first rewrite (A.8) for the three types of agents. Using (A.7) to replace $\mu_{i}$ and (A.9) or (A.10) to eliminate $u_{h s_{i}}^{\prime} / u_{c_{i}}^{\prime}$, equation (A.8) can hence be rewritten as:

$$
-1+\beta_{i}\left[\left(1-\delta_{x}\right)+l\right]+\beta_{i} h_{i} l\left(\frac{1}{\phi}-1\right)+\left[1-\frac{\beta_{i}}{\beta_{1}}\right] m\left(1-\delta_{x}\right)+\frac{\pi_{i}^{x}}{p}=0,
$$


for tenants, and as:

$$
-1+\beta_{i}\left[\left(1-\delta_{x}\right)+l\right]+\beta_{i} \frac{\pi_{i}^{1-h}}{p x_{i}}+\left[1-\frac{\beta_{i}}{\beta_{1}}\right] m\left(1-\delta_{x}\right)=0
$$

for owner-occupiers, and as

$$
-1+\beta_{i}\left[\left(1-\delta_{x}\right)+l\right]+\left[1-\frac{\beta_{i}}{\beta_{1}}\right] m\left(1-\delta_{x}\right)=0
$$

for landlords. Let us now proceed by contradiction. Suppose that the dominant consumer is either a tenant or a owner-occupiers. Using (A.11) and (A.12), this would imply that $-1+$ $\beta_{1}\left[\left(1-\delta_{x}\right)+l\right]<0$, and therefore that equality in (A.13) would be impossible as the LHS would write: $-\left[1-\beta_{i} / \beta_{1}\right]\left[1-m\left(1-\delta_{x}\right)\right]$, and be therefore negative. Thus, the dominant consumer is a landlord, which implies that

$$
-1+\beta_{1}\left[\left(1-\delta_{x}\right)+l\right]=0
$$

and that there is no $\beta_{i}<\beta_{1}$ that can satisfy (A.13).

Claim 3. There exists a unique value for $\beta_{i}$ such that the $x_{i}>0$ and $z_{i}>0$; this value, denoted $\bar{\beta}_{i}$, belongs to $\left(0, \beta_{1}\right)$.

By replacing $\mu_{i}=1-\beta_{i} / \beta_{1}$, (A.10) and (A.14) in (A.8), we obtain the following condition:

$$
\beta_{i} h_{i}\left[(1-\phi) \frac{u_{h s_{i}}^{\prime}}{u_{c_{i}}^{\prime}}-\pi_{i}^{z}\right]-\left[1-\frac{\beta_{i}}{\beta_{1}}\right]\left[1-m\left(1-\delta_{x}\right)\right] p+\pi_{i}^{x}=0
$$

which holds for all $i=2,3, . ., N$. If $x_{i}>0$ and $z_{i}>0$, one has $\pi_{i}^{z}=\pi_{i}^{x}=0, h_{i}=1$ and using (A.10) and (A.14), (A.15) can be rewritten as:

$$
\beta_{i}\left(\frac{1}{\phi}-1\right)\left[\frac{1}{\beta_{1}}-\left(1-\delta_{x}\right)\right]-\left[1-\frac{\beta_{i}}{\beta_{1}}\right]\left[1-m\left(1-\delta_{x}\right)\right]=0
$$

The latter expression hence holds for a unique $\beta_{i}$, denoted $\bar{\beta}_{i}$, which satisfies:

$$
\bar{\beta}_{i}=\beta_{1} \frac{\phi\left[1-m\left(1-\delta_{x}\right)\right]}{\left[(1-\phi)\left[1-\beta_{1}\left(1-\delta_{x}\right)\right]+\phi\left[1-m\left(1-\delta_{x}\right)\right]\right]} .
$$

Using (A.17), it is obvious that $\bar{\beta}_{i} \in\left(0, \beta_{1}\right)$. 
Claim 4. For all $i=2,3, \ldots, N, \pi_{i}^{z}>0$ if $\beta_{i}>\bar{\beta}_{i}$.

The case $\pi_{i}^{z}>0$ corresponds to $z_{i}=\pi_{i}^{x}=0$ and $h_{i}=1$. Using (A.15) and replacing (A.10) and (A.14) in it, we have:

$$
\beta_{i}\left[\left(\frac{1}{\phi}-1\right)\left(\frac{1}{\beta_{1}}-\left(1-\delta_{x}\right)\right)-\frac{\pi_{i}^{z}}{p \phi}\right]-\left[1-\frac{\beta_{i}}{\beta_{1}}\right]\left[1-m\left(1-\delta_{x}\right)\right]=0
$$

from whitch we deduce that $\pi_{i}^{z} \geq 0$ if and only if $\beta_{i} \geq \bar{\beta}_{i}$.

Proof of Proposition 3. In the neighborhood of the deterministic steady state, the partition of the population described in Proposition 2 still holds, and in particular, the dominant consumer is the a unique landlord. The first order conditions (A.1) and (A.3) of this agent can be rewritten as:

$$
1-\frac{\mathbb{E}_{t} \beta_{1 t+1} R_{t} u_{c_{1 t+1}}^{\prime}}{u_{c_{1 t}}^{\prime}}=0 \quad \text { and } \quad-p_{t} l_{t}+\frac{u_{h s_{1 t}}^{\prime}}{u_{c_{1 t}}^{\prime}}=0
$$

which can be replaced in (A.2) to obtain (2).

\section{B Derivation of the model of Section 3}

This section describes the first-order conditions, constraints, production functions, shocks and market clearing conditions that define the equilibrium.

\section{B.1 First order conditions of agent 1}

The Lagrangean is:

$$
\begin{aligned}
& \mathcal{L}=\mathbb{E}_{0} \sum_{t=0}^{\infty} \beta_{1}^{t} \tilde{\beta}_{t}\left[\ln c_{1 t}+j_{t} \ln \left(h_{t} x_{1 t-1}\right)-\chi_{1} \frac{n_{1 t}^{\eta}}{\eta}\right] \\
& +\beta_{1}^{t} \tilde{\beta}_{t} \lambda_{1 t}\left(p_{t}\left[\left(1-\delta_{x}\right)+l_{t}\left(1-h_{t}\right)\right] x_{1 t-1}+r_{t}^{c} k_{t-1}^{c}+r_{t}^{h} k_{t-1}^{h}+p_{t}^{q}\left(1+l_{t}^{q}\right) q_{t-1}\right. \\
& \left.+d_{1 t}+w_{t} n_{1 t}-c_{1 t}-R_{t-1}^{d} d_{1 t-1}-i_{t}^{c}-i_{t}^{h}-p_{t} x_{1 t}-p_{t}^{q} q_{t}-\frac{\phi_{x} p_{t}\left(x_{1 t}-x_{1 t-1}\right)^{2}}{2}\right) \\
& +\beta_{1}^{t} \tilde{\beta}_{t} \lambda_{1 t} p_{t}^{k c}\left(\Upsilon_{t}^{c} i_{t}^{c}\left[1-\frac{\phi_{c}}{2}\left(\frac{i_{t}^{c}}{i_{t-1}^{c}}-1\right)^{2}\right]+\left(1-\delta_{c}\right) k_{t-1}^{c}-k_{t}^{c}\right) \\
& +\beta_{1}^{t} \tilde{\beta}_{t} \lambda_{1 t} p_{t}^{k h}\left(\Upsilon_{t}^{h} i_{t}^{h}\left[1-\frac{\phi_{h}}{2}\left(\frac{i_{1 t}^{h}}{i_{t-1}^{h}}-1\right)^{2}\right]+\left(1-\delta_{h}\right) k_{t-1}^{h}-k_{t}^{h}\right)
\end{aligned}
$$


where $\lambda_{1 t}, \lambda_{1 t} Q_{t}^{c}$ and $\lambda_{1 t} Q_{t}^{h}$ are the multiplyiers associated with constraints (8) and (10). The first-order conditions with respect to $c_{1 t}, h_{t}, n_{1 t}, x_{1 t}, d_{1 t}, q_{t}, i_{t}^{s}$ and $k_{t}^{s}$ with $s=\{c, h\}$, are given by:

$$
\begin{aligned}
& \frac{1}{c_{1 t}}-\lambda_{1 t}=0 \\
& \frac{j_{t}}{h_{1 t}}-\lambda_{1 t} p_{t} l_{t} x_{1 t-1}=0 \\
& \chi_{1} n_{1 t}^{\eta-1}-\lambda_{1 t} w_{t}=0 \\
& p_{t}\left[1+\phi_{x}\left(x_{1 t}-x_{1 t-1}\right)\right]-\beta_{1} \mathbb{E}_{t} \frac{\tilde{\beta}_{t+1}}{\tilde{\beta}_{t}} \frac{\lambda_{1 t+1}}{\lambda_{1 t}} \times \\
& {\left[\frac{j_{t+1}}{x_{1 t} \lambda_{1 t+1}}+p_{t+1}\left[1-\delta_{x}+l_{t+1}\left(1-h_{t+1}\right)\right]+\phi_{x} p_{t+1}\left(x_{1 t+1}-x_{1 t}\right)\right]=0,} \\
& \tilde{\beta}_{t} \lambda_{1 t}-\beta_{1} R_{t}^{d} \mathbb{E}_{t} \tilde{\beta}_{t+1} \lambda_{1 t+1}=0, \\
& \lambda_{1 t} \tilde{\beta}_{t} p_{t}^{q}-\beta_{1} \mathbb{E}_{t} \lambda_{1 t+1} \tilde{\beta}_{t+1} p_{t+1}^{q}\left(1+l_{t+1}^{q}\right)=0 \\
& -1+p_{t}^{k s} \Upsilon_{t}^{s}\left[1-\frac{\phi_{s}}{2}\left(\frac{i_{t}^{s}}{i_{t-1}^{s}}-1\right)^{2}-\phi_{s}\left(\frac{i_{t}^{s}}{i_{t-1}^{s}}-1\right) \frac{i_{t}^{s}}{i_{t-1}^{s}}\right] \\
& \quad+\beta_{1} \mathbb{E}_{t} \frac{\tilde{\beta}_{t+1}}{\tilde{\beta}_{t}} \frac{\lambda_{1 t+1}}{\lambda_{1 t}} p_{t+1}^{k s} \Upsilon_{t+1}^{s} \phi_{s}\left(\frac{i_{t+1}^{s}}{i_{t}^{s}}-1\right)\left(\frac{i_{t+1}^{s}}{i_{t}^{s}}\right)^{2}=0, \\
& p_{t}^{k s}-\beta_{1} \mathbb{E}_{t} \frac{\tilde{\beta}_{t+1}}{\tilde{\beta}_{t}} \frac{\lambda_{1 t+1}}{\lambda_{1 t}}\left[p_{t+1}^{k s}\left(1-\delta_{s}\right)+r_{t+1}^{s}\right]=0 .
\end{aligned}
$$

Using (B.2), conditions (B.3), (B.4), (B.6), (B.7), (B.8) and (B.9) can be rewritten as:

$$
\begin{aligned}
& p_{t} l_{t} h_{t} x_{1 t-1}=j_{t} c_{1 t}, \\
& \chi_{1} n_{1 t}^{\eta-1}=\frac{w_{t}}{c_{1 t}}, \\
& 1=R_{t}^{d} \beta_{1} \mathbb{E}_{t} \frac{\tilde{\beta}_{t+1}}{\tilde{\beta}_{t}} \frac{c_{1 t}}{c_{1 t+1}}, \\
& 1=\beta_{1} \mathbb{E}_{t} \frac{\tilde{\beta}_{t+1}}{\tilde{\beta}_{t}} \frac{c_{1 t}}{c_{1 t+1}} \frac{p_{t+1}^{q}}{p_{t}^{q}}\left(1+l_{t+1}^{q}\right), \\
& 1=p_{t}^{k s} \Upsilon_{t}^{s}\left[1-\frac{\phi_{s}}{2}\left(\frac{i_{t}^{s}}{i_{t-1}^{s}}-1\right)^{2}-\phi_{s}\left(\frac{i_{t}^{s}}{i_{t-1}^{s}}-1\right) \frac{i_{t}^{s}}{i_{t-1}^{s}}\right] \\
& +\beta_{1} \mathbb{E}_{t} \frac{\tilde{\beta}_{t+1}}{\tilde{\beta}_{t}} \frac{c_{1 t}}{c_{1 t+1}} p_{t+1}^{k s} \Upsilon_{t+1}^{s} \phi_{s}\left(\frac{i_{t+1}^{s}}{i_{t}^{s}}-1\right)\left(\frac{i_{t+1}^{s}}{i_{t}^{s}}\right)^{2}, \\
& p_{t}^{k s}=\beta_{1} \mathbb{E}_{t} \frac{\tilde{\beta}_{t+1}}{\tilde{\beta}_{t}} \frac{c_{1 t}}{c_{1 t+1}}\left[p_{t+1}^{k s}\left(1-\delta_{s}\right)+r_{t+1}^{s}\right],
\end{aligned}
$$

while using (B.2) and (B.3), condition (B.5) can be rewritten as:

$$
\left[1+\phi_{x}\left(x_{1 t}-x_{1 t-1}\right)\right]=\beta_{1} \mathbb{E}_{t} \frac{\tilde{\beta}_{t+1}}{\tilde{\beta}_{t}} \frac{c_{1 t}}{c_{1 t+1}} \frac{p_{t+1}}{p_{t}}\left[\left(1-\delta_{x}+l_{t+1}\right)+\phi_{x}\left(x_{1 t+1}-x_{1 t}\right)\right]
$$


There are therefore 13 equations given by (8), (10), (B.2) and (B.10)-(B.16).

\section{B.2 First order conditions of agent 2}

The Lagrangean is:

$$
\begin{aligned}
\mathcal{L} & =\mathbb{E}_{0} \sum_{t=0}^{\infty} \beta_{2}^{t} \tilde{\beta}_{t}\left[\ln c_{2 t}+j_{t} \ln x_{2 t-1}-\chi_{2} \frac{n_{2 t}^{\eta}}{\eta}\right] \\
& +\beta_{2}^{t} \tilde{\beta}_{t} \lambda_{2 t}\left(p_{t}\left(1-\delta_{x}\right) x_{2 t-1}+d_{2 t}+w_{t} n_{2 t}\right. \\
- & \left.c_{2 t}-R_{t-1}^{d} d_{2 t-1}-p_{t} x_{2 t}-\frac{\phi_{x} p_{t}\left(x_{2 t}-x_{2 t-1}\right)^{2}}{2}\right) \\
& +\beta_{2}^{t} \tilde{\beta}_{t} \lambda_{2 t} \mu_{2 t} \mathbb{E}_{t}\left(m_{t} p_{t+1}\left(1-\delta_{x}\right) x_{2 t}-d_{2 t}\right),
\end{aligned}
$$

where $\lambda_{2 t}$ and $\lambda_{2 t} \mu_{2 t}$ are the multiplyers associated with constraints (12) and (13). The first-order conditions with respect to $c_{2 t}, n_{2 t}, x_{2 t}, d_{2 t}$, are given by:

$$
\begin{aligned}
& \frac{1}{c_{2 t}}=\lambda_{2 t}, \\
& \chi_{2} n_{2 t}^{\eta-1}=\frac{w_{t}}{c_{2 t}}, \\
& p_{t}\left(1+\phi_{x}\left(x_{2 t}-x_{2 t-1}\right)\right)-\mu_{2 t} m_{t}\left(1-\delta_{x}\right) \mathbb{E}_{t} p_{t+1} \\
& =\beta_{2} \mathbb{E}_{t} \frac{\tilde{\beta}_{t+1}}{\tilde{\beta}_{t}}\left[\frac{j_{t+1} c_{2 t}}{x_{2 t}}+\frac{c_{2 t}}{c_{2 t+1}} p_{t+1}\left[1-\delta_{x}+\phi_{x}\left(x_{2 t+1}-x_{2 t}\right)\right]\right], \\
& \mu_{2 t}=1-R_{t}^{d} \beta_{2} \mathbb{E}_{t}\left[\frac{\tilde{\beta}_{t+1}}{\tilde{\beta}_{t}} \frac{c_{2 t}}{c_{2 t+1}}\right] .
\end{aligned}
$$

There are therefore 6 equations given by (12), (13) and (B.17)-(B.20).

\section{B.3 First order conditions of agent 3}

The Lagrangean is:

$$
\mathcal{L}=\ln c_{3 t}+j \ln \left(\phi z_{t}\right)-\chi_{3} \frac{n_{3 t}^{\eta}}{\eta}+\lambda_{3 t}\left[w_{t} n_{3 t}-c_{3 t}-p_{t} l_{t} z_{t}\right]
$$

where $\lambda_{3 t}$ is the multiplyer associated to (15). The first-order conditions with respect to $z_{t}$ and $n_{3 t}$ are:

$$
\begin{aligned}
-\frac{p_{t} l_{t}}{c_{3 t}}+j \frac{1}{z_{t}} & =0 \\
-\chi_{3} n_{3 t}^{\eta-1}+\frac{w_{t}}{c_{3 t}} & =0 .
\end{aligned}
$$


There are therefore 3 equations given by (15), (B.22) and (B.23).

\section{B.4 First order conditions of firms}

Profit in the consumption sector is written as:

$$
A_{c t} K_{c t}^{\gamma_{c}} L_{c t}^{\alpha_{c}}-r_{t}^{c} K_{c t}-w_{t} L_{c t}
$$

Its maximization implies that the following conditions are satisfied:

$$
\begin{aligned}
\gamma_{c} \frac{Y_{c t}}{K_{c t}} & =r_{t}^{c}, \\
\alpha_{c} \frac{Y_{c t}}{L_{c t}} & =w_{t} .
\end{aligned}
$$

Profit in the housing sector is:

$$
p_{t} A_{h t} K_{h t}^{\gamma_{h}} L_{h t}^{\alpha_{h}} Q_{t}^{1-\alpha_{h}-\gamma_{h}}-r_{t}^{h} K_{h t}-w_{t} L_{h t}-p_{t}^{q} l_{t}^{q} Q_{t}
$$

The maximization implies:

$$
\begin{aligned}
\gamma_{h} \frac{Y_{h t}}{K_{h t}} & =\frac{r_{t}^{h}}{p_{t}} \\
\alpha_{h} \frac{Y_{h t}}{L_{h t}} & =\frac{w_{t}}{p_{t}} \\
\left(1-\alpha_{h}-\gamma_{h}\right) \frac{Y_{h t}}{Q_{t}} & =\frac{p_{t}^{q} l_{t}^{q}}{p_{t}}
\end{aligned}
$$

\section{Data}

\section{C.1 Data sources for estimation and computation of moments}

Data for the estimation and the computation of moments stem from the following sources (in italics, we indicate for which variable these data are used):

- Board of Governors of the Federal Reserve System (US), 3-Month Treasury Bill: Secondary Market Rate [TB3MS], retrieved from FRED, Federal Reserve Bank of St. Louis; https: 
//fred.stlouisfed.org/series/TB3MS, January 14, 2021. Used to construct the series for the interest rate.

- Board of Governors of the Federal Reserve System (US), Households and Nonprofit Organizations; One-to-Four-Family Residential Mortgages; Liability, Level [HHMSDODNS], retrieved from FRED, Federal Reserve Bank of St. Louis; https://fred.stlouisfed.org/series/ HHMSDODNS, January 14, 2021. Used to construct the series for household's debt.

- Lincoln Institute of Land Policy, rent-price ratio (FHFA serie) https://www.lincolninst. edu Used to construct the series for the rent-price ratio.

- U.S. Bureau of Economic Analysis, "Table 1.1. Current-Cost Net Stock of Fixed Assets and Consumer Durable Goods" (accessed January 14, 2021). Used to compute ratio of residential real estate over output in calibration.

- U.S. Bureau of Economic Analysis, "Table 1.1.5. Gross Domestic Product" (accessed January 14, 2021). Used to construct the series for consumption, residential and non-residential investments and output.

- U.S. Bureau of Labor Statistics, Nonfarm Business Sector: Implicit Price Deflator [IPDNBS], retrieved from FRED, Federal Reserve Bank of St. Louis; https://fred.stlouisfed.org/ series/IPDNBS, January 14, 2021. Used as price deflator.

- U.S. Bureau of Labor Statistics, Population Level [CNP16OV], retrieved from FRED, Federal Reserve Bank of St. Louis; https://fred.stlouisfed.org/series/CNP160V, January14, 2021. Used to express aggregates in per capita terms.

- U.S. Census Bureau, Homeownership Rate for the United States [RHORUSQ156N], retrieved from FRED, Federal Reserve Bank of St. Louis; https://fred.stlouisfed.org/series/ RHORUSQ156N, January 14, 2021..$^{53}$ Used to construct series on homeownership rate.

\footnotetext{
${ }^{53}$ These data have been further deseasonalized using The the X-13ARIMA-SEATS Seasonal Adjustment Program (https://www. census.gov/srd/www/x13as/)
} 
- U.S. Census Bureau house price index on single family homes: https://www.census.gov/ construction/nrs/historical_data/index.html Used to construct series for house prices.

\section{C.2 Construction of data used for estimation and moments}

To estimate the model and compute moments, we compute aggregates at quarterly frequency (when annualized), express them in real terms and in per capita terms when appropriate. Here is a summary of how the aggregates are computed in the paper:

- Consumption: BEA seasonally adjusted data on personal consumption expenditures deflated by the non-farm business sector implicit price deflator and divided by the US non-institutional population

- Non-residential investment: BEA seasonally adjusted data on non-residential fixed investment deflated by the non-farm business sector implicit price deflator and divided by the US non-institutional population

- Residential investment: BEA seasonally adjusted data on residential fixed investment deflated by the non-farm business sector implicit price deflator and divided by the US noninstitutional population

- GDP: BEA seasonally adjusted data on GDP deflated by the non-farm business sector implicit price deflator and divided by the US non-institutional population

- House prices: U.S. Census Bureau house price index divided by implicit price deflator

- Rent-price ratio: rent-price ratio from Lincoln Institute

- Real interest rate: constructed from 3-month T-bill and one-quarter ahead change in the non-farm business sector implicit price deflator

- Debt: series for One-to-Four-Family Residential Mortgages divided deflated by the non-farm business sector implicit price deflator and divided by the US non-institutional population 


\section{C.3 Data Sources for Figure 5}

The sources used to construct figure 5 are:

- For house prices: U.S. Federal Housing Finance Agency, Purchase Only House Price Index for the United States [HPIPONM226S], retrieved from FRED, Federal Reserve Bank of St. Louis; https://fred.stlouisfed.org/series/HPIPONM226S, January 14, 2021.

- For rent-price ratio: U.S. Bureau of Labor Statistics, Consumer Price Index for All Urban Consumers: Rent of Primary Residence in U.S. City Average [CUUR0000SEHA], retrieved from FRED, Federal Reserve Bank of St. Louis; https://fred.stlouisfed.org/series/ CUUR0000SEHA,January 14, 2021. (NB: we divide this series by the above series for house prices to obtain the rent-price ratio)

- For interest rate: Board of Governors of the Federal Reserve System (US), 3-Month Treasury Bill: Secondary Market Rate [TB3MS], retrieved from FRED, Federal Reserve Bank of St. Louis; https://fred.stlouisfed.org/series/TB3MS, January 14, 2021.

- For household debt: Board of Governors of the Federal Reserve System (US), Households and Nonprofit Organizations; One-to-Four-Family Residential Mortgages; Liability, Level [HHMSDODNS], retrieved from FRED, Federal Reserve Bank of St. Louis; https: //fred.stlouisfed.org/series/HHMSDODNS, January, 2021.

- For residential investment: U.S. Bureau of Economic Analysis, Private Residential Fixed Investment [PRFI], retrieved from FRED, Federal Reserve Bank of St. Louis; https://fred. stlouisfed.org/series/PRFI, January 14, 2021. 


\section{Robustness}

\section{D.1 Alternative period not including the Great Recession}

Table D.1 checks the ability of our model to match the data from the period before the Great Recession (1965-2006). The first column provides the moments for our series (1965-2006). Columns 2 and 3 show the simulation results for our model estimated on the series of the same time interval, by using a first order and second order approximation, respectively.

This shorter period is characterized (perhaps unsurprisingly) by less volatility for house prices, the rent-price ratio, residential investment and household debt relative to the results we obtain for the period 1965-2016 in the main text. One noticeable difference compared with the longer time period is that the correlation between house prices and interest rates is here -0.10 (thus slightly negative) while it is 0.04 (thus slightly positive) for the 1965-2016 period. Our model tends to deliver on average a slightly negative correlation between house prices and interest rates in both the estimation in the main text and the one in this section. One explanation is that we do not have price rigidities nor monetary policies and thus cannot account for some of the non-linearities associated with hitting the zero lower bound. 
Table D.1: Baseline model, moments for period 1965-2006.

\begin{tabular}{cc}
\hline Data & \multicolumn{2}{c}{ Baseline model } \\
\cline { 2 - 2 } & \\
\hline
\end{tabular}

$\begin{array}{lll}\text { Std output } \quad 1.75 & 1.02 & 1.04\end{array}$

Standard deviations relative to output:

$\begin{array}{llll}\text { House prices } & 1.19 & 1.27 & 1.54 \\ \text { Rent-price ratio } & 1.54 & 1.57 & 1.78 \\ \text { Consumption } & 0.83 & 0.82 & 0.81 \\ \text { Non-residential investment } & 2.52 & 2.92 & 2.97 \\ \text { Residential investment } & 5.89 & 7.06 & 9.82 \\ \text { Private debt } & 1.57 & 1.41 & 1.84 \\ \text { Interest rate } & 0.21 & 0.36 & 0.36\end{array}$

Cross-correlation between output and

$\begin{array}{llll}\text { Consumption } & 0.92 & 0.83 & 0.80 \\ \text { Residential investment } & 0.72 & 0.44 & 0.40 \\ \text { Non-residential invesment } & 0.70 & 0.69 & 0.69 \\ \text { House prices } & 0.59 & 0.31 & 0.17\end{array}$

Cross-correlation between house prices and

$\begin{array}{lccc}\text { Consumption } & 0.44 & 0.38 & 0.32 \\ \text { Residential investment } & 0.45 & 0.40 & 0.06 \\ \text { Rent-price ratio } & -0.58 & -0.05 & -0.32 \\ \text { Interest rates } & -0.10 & -0.19 & -0.15\end{array}$

"Data": Data include series for the period 1965-2006. "1st order": predictions from model simulated with a first order approximation. "2nd order": predictions from model simulated with a second order approximation with pruning. Results are provided after all shocks. Results come from a simulation of the model of a 30000-periods length. The first 500 periods have been truncated. HP filter, lambda $=1600$. Aggregates are expressed in per capita units.

\section{D.2 Alternative series for house prices}

Table D.2 provides the moments calculated on series for the periods 1965-2006 and 1965-2016 respectively. The series we use are the same as the ones in our baseline estimation except for house prices. We use here the FHFA series from the Lincoln Institute.

The model is overall quite successful in matching the data moments with this alternative series. This series tends to be less correlated with residential investment which is reflected also in our estimated model (although, as for the baseline we tend to underestimate the positive correlation 
between house prices and residential investment). It is also more negatively correlated with the rent-price ratio and the interest rate, which is also reflected in our model. Finally, this series is more volatile than our baseline series for house prices, and our model tends to underestimate this volatility. Nonetheless, our model remains quite successful in matching the most salient features of the data.

Table D.2: Baseline model, moments (FHFA house prices).

\begin{tabular}{lcccc}
\hline & \multicolumn{2}{c}{$1965-2006$} & \multicolumn{2}{c}{$1965-2016$} \\
\cline { 2 - 5 } & Data & Model & Data & Model \\
\hline \multirow{2}{*}{ Std output } & 1.75 & 1.03 & 1.69 & 1.03 \\
Standard deviations relative to output: & & \\
House prices & & & & \\
Rent-price ratio & 1.66 & 1.19 & 2.14 & 1.25 \\
Consumption & 1.54 & 1.34 & 2.05 & 1.40 \\
Non-residential investment & 2.52 & 2.96 & 2.77 & 3.02 \\
Residential investment & 5.89 & 7.57 & 6.91 & 7.75 \\
Private debt & 1.57 & 1.43 & 1.88 & 1.49 \\
Interest rate & 0.21 & 0.31 & 0.21 & 0.30
\end{tabular}

Cross-correlation between output and

$\begin{array}{lllll}\text { Consumption } & 0.92 & 0.81 & 0.93 & 0.80 \\ \text { Residential investment } & 0.72 & 0.42 & 0.70 & 0.41 \\ \text { Non-residential invesment } & 0.70 & 0.69 & 0.70 & 0.71 \\ \text { House prices } & 0.55 & 0.24 & 0.56 & 0.22\end{array}$

Cross-correlation between house prices and

$\begin{array}{lcccc}\text { Consumption } & 0.49 & 0.42 & 0.50 & 0.38 \\ \text { Residential investment } & 0.30 & 0.09 & 0.54 & 0.23 \\ \text { Rent-price ratio } & -0.90 & -0.62 & -0.95 & -0.66 \\ \text { Interest rates } & -0.25 & -0.22 & -0.04 & -0.19\end{array}$

"Data": Data include series for the period 1965-2006 and 1965-2016, respectively. Predictions from model simulated with a second order approximation with pruning. Results are provided after all shocks. Results come from a simulation of the model of a 30000-periods length. The first 500 periods have been truncated. HP filter, lambda $=1600$. Aggregates are expressed in per capita units. For house prices, we use the FHFA series from the Lincoln Institute.

\section{D.3 Model with shocks to the collateral constraint}

Table D.3 shows the moments for an estimated version of the model in which we allow for a stochastic loan-to-value parameter in the collateral constraint. This model tends to generate too 
much volatility with respect to the data, especially for house prices, residential investment, private debt and interest rates.

Table D.3: Model with shocks to collateral constraint, moments for period 1965-2016.

\begin{tabular}{cc}
\hline Data & \multicolumn{2}{c}{ Baseline model } \\
\cline { 2 - 2 } & 1st order 2nd order \\
\hline
\end{tabular}

$\begin{array}{lll}\text { Std output } \quad 1.69 & 1.02 & 1.04\end{array}$

Standard deviations relative to output:

$\begin{array}{lccc}\text { House prices } & 1.57 & 1.53 & 2.25 \\ \text { Rent-price ratio } & 2.05 & 1.76 & 2.38 \\ \text { Consumption } & 0.84 & 0.81 & 0.80 \\ \text { Non-residential investment } & 2.77 & 3.12 & 3.17 \\ \text { Residential investment } & 6.91 & 7.66 & 12.88 \\ \text { Private debt } & 1.88 & 2.50 & 3.23 \\ \text { Interest rate } & 0.21 & 0.46 & 0.49\end{array}$

Cross-correlation between output and

$\begin{array}{llll}\text { Consumption } & 0.93 & 0.80 & 0.76 \\ \text { Residential investment } & 0.70 & 0.35 & 0.33 \\ \text { Non-residential invesment } & 0.70 & 0.70 & 0.69 \\ \text { House prices } & 0.53 & 0.21 & 0.05\end{array}$

Cross-correlation between house prices and

$\begin{array}{lccc}\text { Consumption } & 0.45 & 0.30 & 0.25 \\ \text { Residential investment } & 0.63 & 0.33 & -0.10 \\ \text { Rent-price ratio } & -0.76 & -0.23 & -0.62 \\ \text { Interest rates } & 0.04 & -0.07 & -0.05\end{array}$

Notes: Data include series for the period 1965-2016. "1st order": predictions from model simulated with a first order approximation. "2nd order": predictions from model simulated with a second order approximation with pruning. Results are provided after all shocks. Results come from a simulation of the model of a 30000-periods length. The first 500 periods have been truncated. HP filter, lambda $=1600$. Aggregates are expressed in per capita units. 